\author{
WALDEN \\ UNIVERSITY \\ A higher degree. A higher purpose.
}

Walden University ScholarWorks

Walden Dissertations and Doctoral Studies

2019

\title{
Exploring Perceptions of the Transition From Health Science Practitioner to Academic
}

MaryAnne J. Stewart

Walden University

Follow this and additional works at: https://scholarworks.waldenu.edu/dissertations

Part of the Adult and Continuing Education Administration Commons, and the Adult and Continuing Education and Teaching Commons

This Dissertation is brought to you for free and open access by the Walden Dissertations and Doctoral Studies Collection at ScholarWorks. It has been accepted for inclusion in Walden Dissertations and Doctoral Studies by an authorized administrator of ScholarWorks. For more information, please contact ScholarWorks@waldenu.edu. 


\title{
Walden University
}

\author{
College of Education
}

This is to certify that the doctoral study by

MaryAnne Stewart

has been found to be complete and satisfactory in all respects, and that any and all revisions required by the review committee have been made.

Review Committee

Dr. Edward Kim, Committee Chairperson, Education Faculty

Dr. Stephen Butler, Committee Member, Education Faculty

Dr. Shannon Decker, University Reviewer, Education Faculty

\section{Chief Academic Officer \\ Eric Riedel, Ph.D.}

Walden University

2019 


\begin{abstract}
Exploring Perceptions of the Transition From Health Science Practitioner to Academic by

MaryAnne Stewart
\end{abstract}

MBA, University of Phoenix, 2006

BSc, University of Windsor, 2002

Project Study Submitted in Partial Fulfillment

of the Requirements for the Degree of

Doctor of Education

Walden University

March 2019 


\begin{abstract}
Transitioning from a clinical practitioner to an educator in the health sciences is a difficult task for many professionals. Although, clinically, these individuals have achieved a level of expertise, they are not necessarily trained to teach in a classroom setting and may find it difficult to transition into their role as novice. The purpose of this qualitative case study was to examine faculty members' preparedness during their transition to academia and their perceptions of the need for more support during the first 5 years of teaching. Vygotsky's and Dewey's theories of social constructivism and Knowles's assumptions of adult learning provided the framework for this research. The main research question focused on exploring perceptions about instructional preparedness and support for university educators, at a university in Detroit, Michigan, in health science fields. The data sources were interviews and observations from 9 health science faculty members. Interviews were coded based on perceptive categories such as experiences, knowledge, and opinions, whereas observations were coded using recurrent patterns of identified standards of university teaching based on teaching preparedness. Results showed 5 areas where the participants felt they needed more support: peer mentoring, administration support, institutional support, interaction with students, and instructional methodology technology training. Findings may provide insight to university administrators on strategies to provide more effective professional development to health science educators. Potential implications for positive social change include increased job satisfaction and retention for professionals who become health science educators.
\end{abstract}


Exploring Perceptions of the Transition From Health Science Practitioner to Academic by

MaryAnne Stewart

MBA, University of Phoenix, 2006

BSc, University of Windsor, 2002

Project Study Submitted in Partial Fulfillment of the Requirements for the Degree of

Doctor of Education

Walden University

March 2019 
Table of Contents

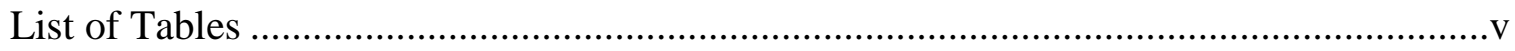

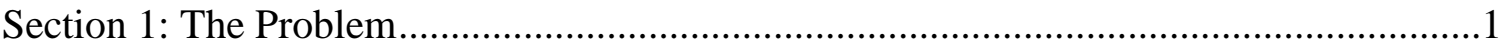

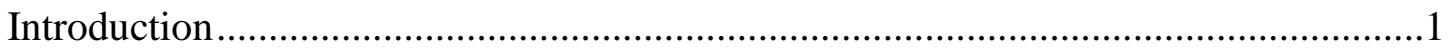

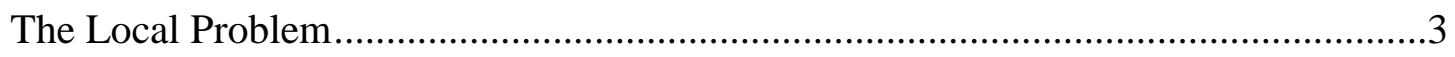

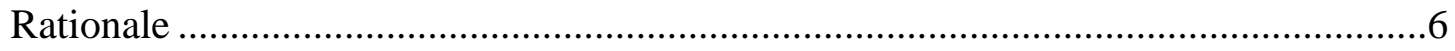

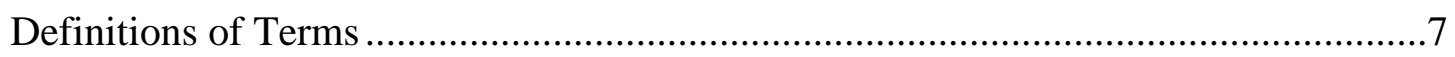

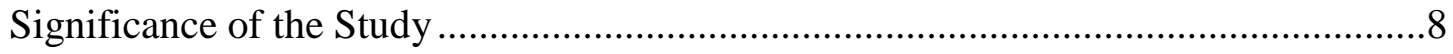

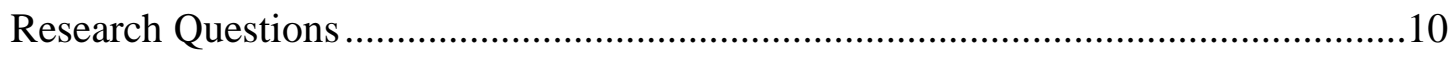

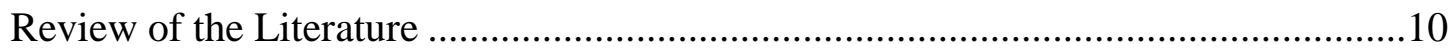

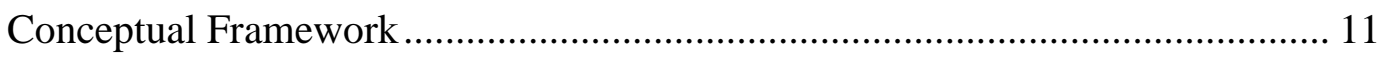

Academic Institutions of Higher Learning ............................................... 13

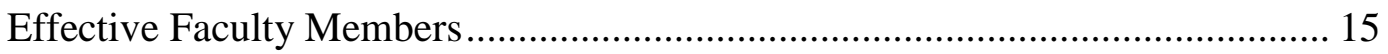

Support for Junior Faculty Members .................................................... 16

First Teaching Experiences ...................................................................... 17

The Need for Mentorship and Professional Development................................ 23

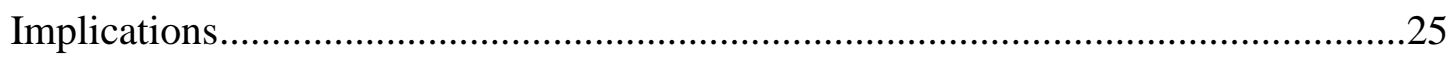

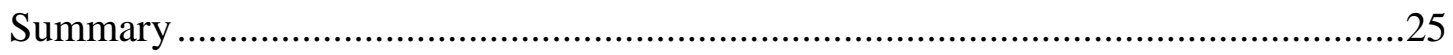

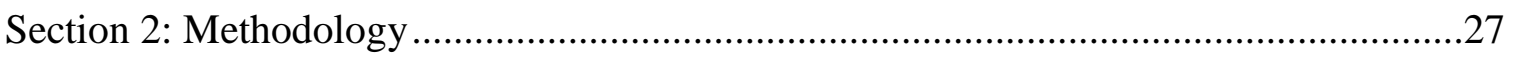

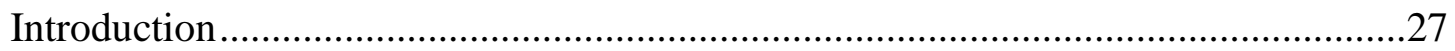

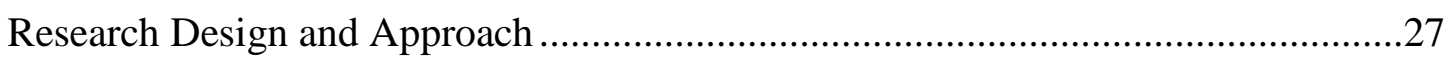

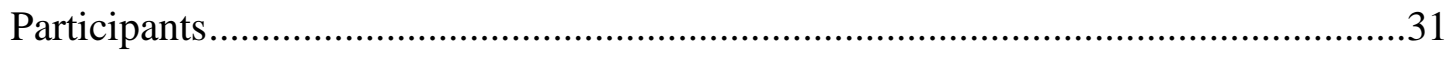




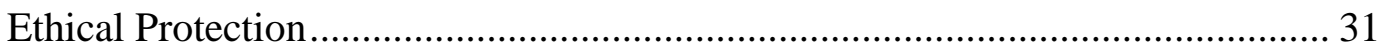

Access to the Participants ................................................................................. 32

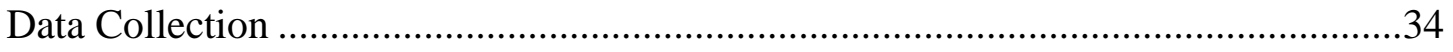

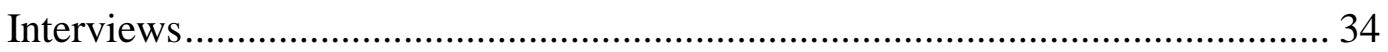

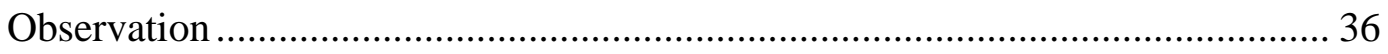

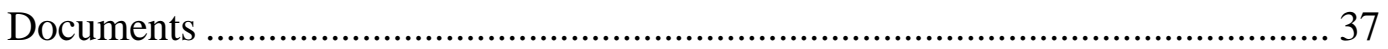

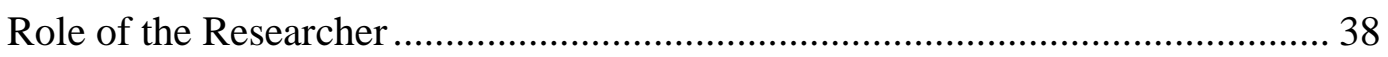

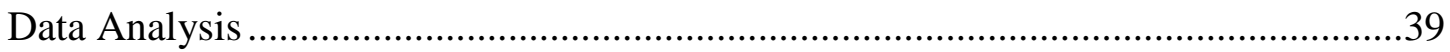

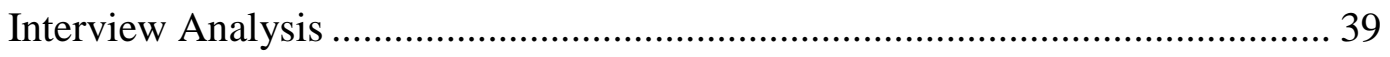

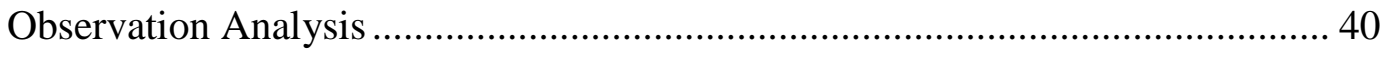

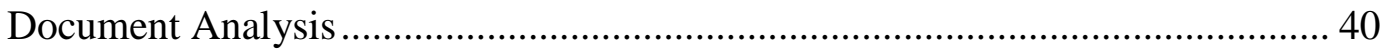

Data Results from Interviews and Observations................................................. 41

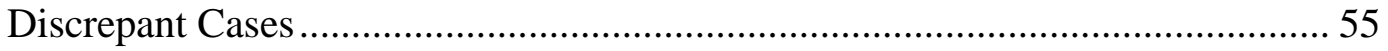

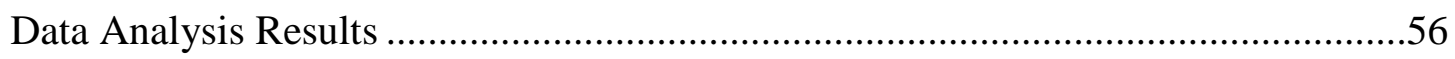

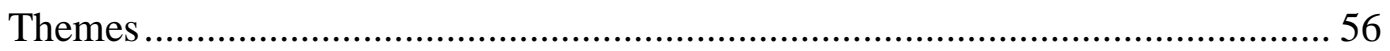

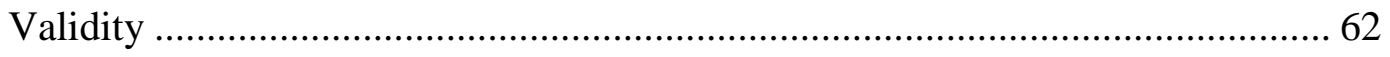

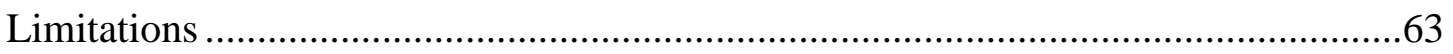

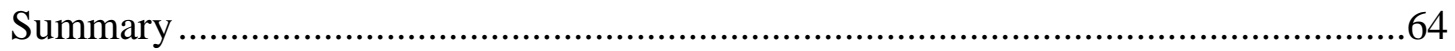

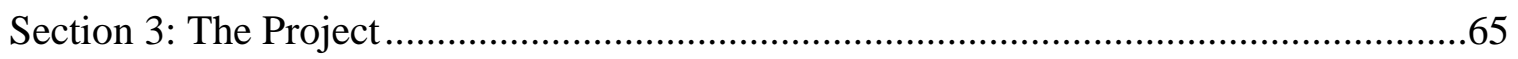

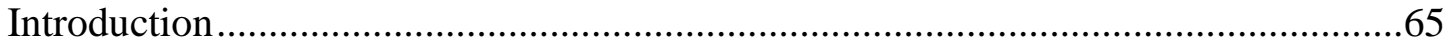

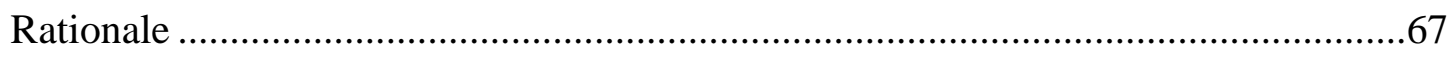

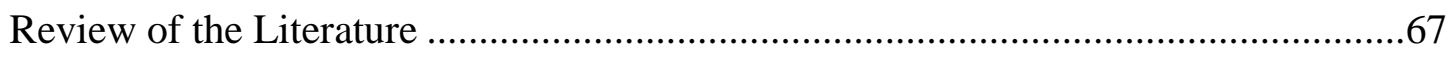




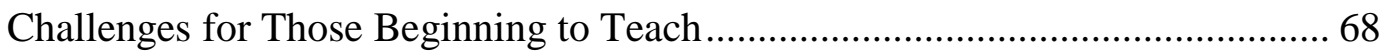

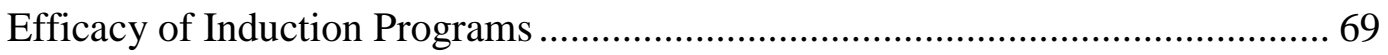

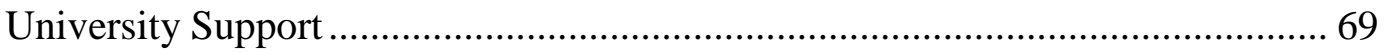

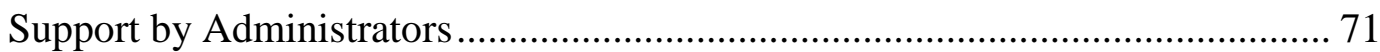

Support by Peer Mentors ............................................................................... 71

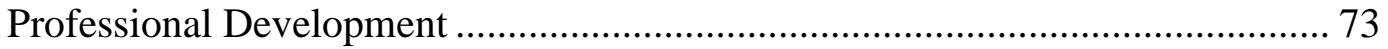

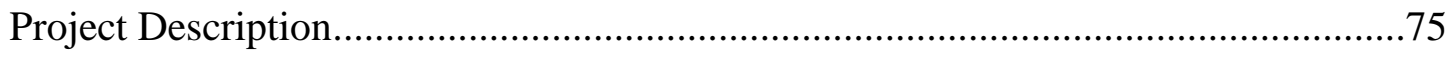

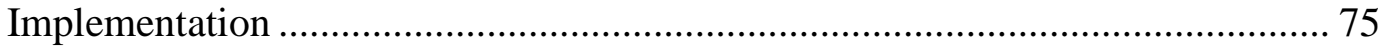

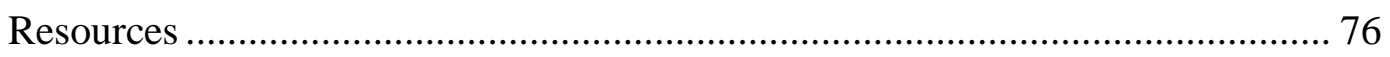

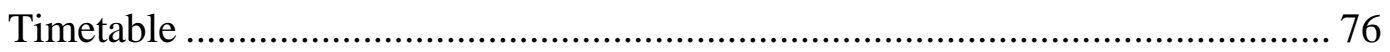

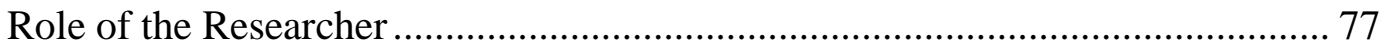

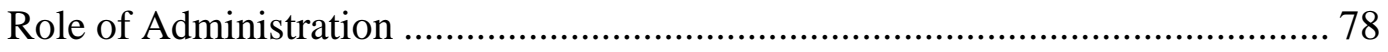

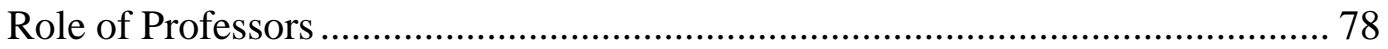

Project Evaluation Plan........................................................................................

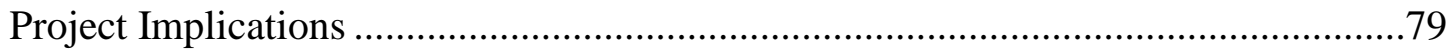

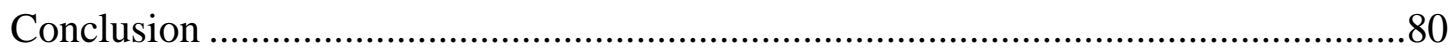

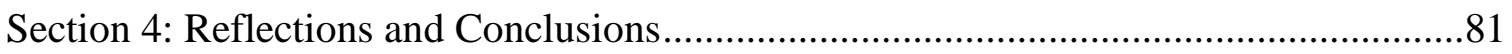

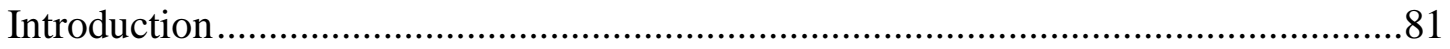

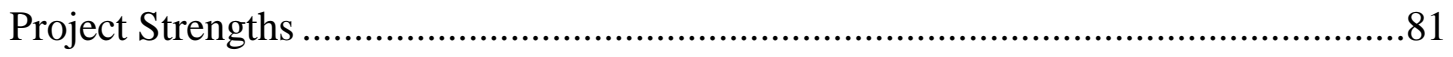

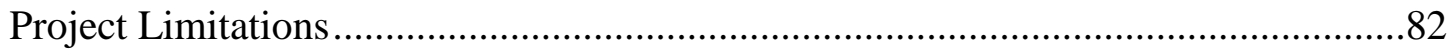

Recommendations for Alternative Approaches ……………...................................82

Scholarship, Project Development, and Leadership and Change ..................................83 


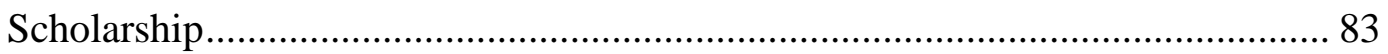

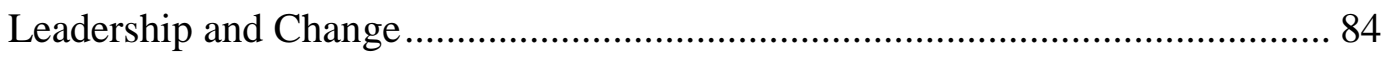

Reflection on the Importance of the Work ................................................................85

Implications, Application, and Directions for Future Research ..................................86

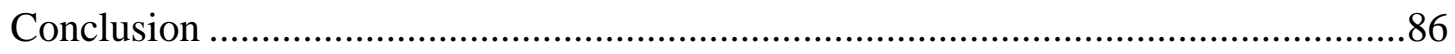

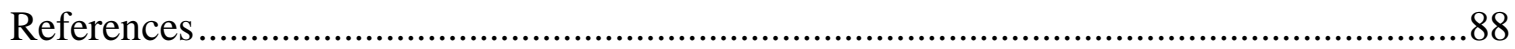

Appendix A: Access to Participants ……………………….....................................103

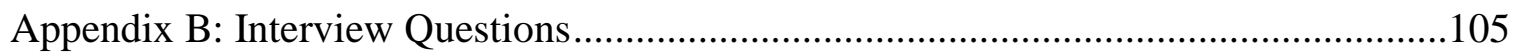

Appendix C: Field Note Observational Data ………………....................................107

Appendix D: The Project PowerPoint........................................................................108 


\section{List of Tables}

Table 1. Faculty Counts, Wayne State University (2010-2016) ....................................4 
Section 1: The Problem

\section{Introduction}

The initial years of teaching for health science teachers are the most difficult period of their development, according to Fain (2011). During this time, novices try to adapt from a clinical setting to the realities of the classroom. They need to be prepared in the transfer of knowledge, instructional preparation, and student success (Howes, 2015). The priority of some American universities on promoting excellence in the delivery of education ) may contribute additional pressure on newly transitioned educators who lack experience in health science teaching, making for a very difficult and stressful period in their lives. According to the human resources postings at a university in Detroit, qualifications for teaching in health sciences include a $\mathrm{PhD}$ or equivalent in a related field with no mention of training in educational theory and methodology

The goal of many contemporary American universities is to educate leaders in their community. To accomplish this goal, teaching effectiveness in required. University leaders must invest in their faculty members by providing them with opportunities to receive instruction in educational theory, instructional methodology, and educational technology, according to Robinson and Hope (2013). The benefits of investing in faculty members not only enhances university status but also creates competent students for the workforce.

An educator's primary responsibility is to facilitate learning. To achieve excellence in his or her field, a teacher must ensure that every student reaches his or her 
potential and ultimately graduates (Glaister, 2013). Instructor's can only elevate a student's potential when they have sufficient teaching skills which include proficient transfer of content knowledge, adaptation to different types of learning behaviors, and understandable subject matter delivery. Students, governments, and universities in the United States have placed an increasing emphasis on high quality and efficient teaching and accountability (Glaister, 2013).

To address any deficiencies in faculty member preparation in instructional technology and theory, leaders of a university in Detroit, Michigan, developed the Office of Teaching and Learning in 1996. The creation of this office was an attempt to support general faculty members by offering workshops and events related to educational technology. With this added service, it would be expected that the overall support for faculty members at the university has improved; however, according to the OTL report few health science faculty members are attending the workshops, as they are not geared toward instructional methodology in the health sciences. Despite the ongoing support available to faculty members from the Office of Teaching and Learning, there continues to be a problem in health science educators' participation in development activities. A possible reason for this issue is that university instructors are only required to have formal content knowledge, not formal instructional experience, according to the university's human resources department. Faculty members may have a negative experience with teaching because, as content experts, they may not know how to transfer knowledge appropriately, they may have a lack of support, and they may not be prepared 
to handle the added stress of a classroom environment (Fain, 2011). In Section 1, I describe the local problem in more detail, provide the rationale, define key terms, discuss the significance of the study, state the research questions, review relevant literature, and consider the implications for this study.

\section{The Local Problem}

A university identified as (WSU) is a community-based public university located in midtown Detroit, Michigan. According to human resources at the project site, in 2018, the school serves 27,000 students in total; the number of students in health-related fields is approximately 800 . Health science or allied health programs are those that train nonmedical and nonnursing practitioners in health care who are educated in universities (Turnbull et al., 2009). In these fields, teaching is tailored toward the needs of the programs and students, and learning is student-centered. The type of instruction requires the use of highly skilled techniques because of the emphasis in each program on student preparation for national board exams (Shaleh, Shabila, Dabbagh, Al-Tawil, \& Al-Hadithi, 2015). There are nine health science related fields at WSU with student cohorts as small as 10 and as large as 150 approximately. The faculty in health science departments are relatively small compared to the other larger departments within the university; therefore, the impact of even a small loss of these faculty members can cause program instability. According to WSU's Office of Institutional Research and Analysis (2017), there was a loss of 23 health science faculty members from 2010 to 2014, representing an $11 \%$ decrease. Health Science departments at WSU can consist of one to 10 faculty members 
(WSU, College of Pharmacy and Health Sciences Faculty, 2017). Table 1 includes the number of overall faculty in comparison to Health Sciences faculty at WSU for 20102016.

Table 1

Faculty Counts, WSU (2010-2016)

\begin{tabular}{llllllll}
\hline & & & & Year & & \\
& 2010 & 2011 & 2012 & 2013 & 2014 & 2015 & 2016 \\
$\begin{array}{l}\text { Faculty } \\
\text { category }\end{array}$ & & & & & & & \\
\hline Overall & 1,816 & 1,806 & 1,783 & 1,755 & 1,728 & 1,680 & 1,668 \\
$\begin{array}{l}\text { Health } \\
\text { Sciences }\end{array}$ & 229 & 230 & 228 & 206 & & & \\
\hline
\end{tabular}

Note. Adapted from the "Office of the Institutional Research and Analysis Dashboard" by WSU, 2017.

For junior health science faculty members, the pressures of promoting excellence in the delivery of education and the lack of experience with teaching may lead to their leaving the institution entirely to go back to clinical practice. The Office of Teaching and Learning at WSU provides programs and workshops across disciplines to enhance teaching. According to annual reports, in 2013-2014, the Office of Teaching and Learning began offering customized workshops for many departments within the university except for the smaller health science-related fields. In the 2014-2015 calendar year, the Office began providing informational technology workshops for health care sciences but no workshops about teaching effectiveness or curriculum development (WSU, Office for Teaching and Learning, 2017). Despite the support from the Office of 
Teaching and Learning available to faculty members on campus, full-time faculty members have not been fully prepared to teach.

In this study, I investigated health science faculty members' perceptions of their preparedness and support during their first 5 years of teaching. Although health science practitioners who become educators of higher learning are content experts with either a master's or a doctoral degree in their respective field, they are not necessarily trained to teach in a classroom setting where the transfer of this knowledge is necessary. In the first years of teaching, they may be hired as full-time faculty members or lecturing staff without any formal education in instructional methodology and educational technology. Health science fields tend to have a smaller cohort; therefore, teaching is adapted toward the needs of the cohort and aligned with student-centered learning (Turnbull et al., 2009). This type of instruction is one of the most challenging and highly skilled teaching techniques in health science education, and it must be executed carefully in order for students to be prepared for national certification exams (Shaleh et al., 2015).

Currently, the Office of Teaching and Learning at the project site provides workshops and events for faculty members on the technology aspects of teaching; however, these workshops are not mandatory nor are they geared toward teaching methodologies for the health science fields (WSU, Office of Teaching and Learning, 2017). This problem not only affects the instructor in his or her support for learning materials; it also affects the student who is the recipient of this material. Many factors that contribute to the perceptions of teaching during those crucial first years may 
influence the decision to stay as an educator or go back to clinical practice. Among these factors are the need for pedagogical training of faculty members (Robinson \& Hope, 2013), the student experience (Barak \& Levenberg, 2016). and the necessity of faculty professional development programs (Bigbee, Rainwater, \& Butani, 2016).

\section{Rationale}

The purpose of this study was to examine university teachers' perceptions of their preparedness to teach as health science-related content experts at WSU during their first 5 years of teaching and provide recommendations for support needed for the profession. Instructors in these programs are given academic freedom to choose the type of material they deem appropriate to develop highly skilled practitioners. Many of the health science discipline-specific programs have small to medium cohorts who require different skills, sophisticated andragogy, the use of class activities, and an understanding of group dynamics on the part of instructors (Murray \& Wolf, 2016). This type of teaching and learning creates highly developed intellectual skills through reasoning and problemsolving, which makes this kind of teaching one of the most challenging and highly skilled teaching techniques (Shaleh et al., 2015). Yet, many health sciences faculty members do not have the opportunity to experience the classroom setting and observe teaching styles, according to Turnbull (2009). They lack the experience of an academic setting and realize quickly how different the setting is from the clinical environment. Without knowledge of instructional methodology and the freedom to choose the materials they deem neccesary, they may not fully understand how, or be able, to effectively teach in these challenging 
programs (Roberts, 2015). In this study, I investigated the experiences of these teachers and offered recommendations for increasing the support provided to health science educators at higher learning institutions. This research was worthy of exploration, I believe, because it can affect current and future faculty members and their students.

\section{Definitions of Terms}

Throughout this study, I use terms that are relevant to the field of education. Their descriptions follow.

Content expert: Faculty members who are well versed in the subject matter knowledge they are presenting (Krajewski \& Schwartz, 2014).

Induction: The initial years of teaching during which faculty members adapt ideas from preparatory programs to the realities of the classroom (Saka et al., 2012).

Instructional methodology: The ability to cognitively transfer knowledge or skills from a task to another within a classroom (Nokes-Malach \& Mestre, 2013).

Junior faculty member: For the purposes of this study, a junior faculty member is one who is transitioning from the clinical setting to academia and is in the first 5 years of teaching.

Mentor: A seasoned faculty member who contributes to the significant growth and nurturing of a colleague with a broader goal of promoting strong teaching pedagogy (Starr \& DeMartini, 2015). 
Offices of teaching and learning: Service providers within university

infrastructures that offer venues, workshops, learning communities, and consultations that support faculty to become scholars of teaching and learning (Calderwood \& Klaf, 2014).

Professional development: The provision of opportunities for teachers to improve their instruction, add skills, and increase the value to the profession (Hentges, 2012).

Teaching effectiveness: Characteristics that are regarded as constituting exemplary performance of faculty members - for example, when they have a deep concern for the student, demonstrate competence, and demonstrate instructional proficiency (Komos, 2013).

\section{Significance of the Study}

Teacher support has been targeted as an international issue and has been the focus of research in the United States according to the Organization for Economic Cooperation and Development report of 2013. Lack of faculty member preparedness, during their first 5 years of teaching, and the factors that predict them have been studied at the national level (O-Meara, 2013; O'Meara et al., 2014; Ryan et al., 2011). These effects associated with educator preparedness include inexperience of classroom management and an unawareness of resources for new faculty member's success (O-Meara, 2013). The pressures of the newly transitioned educator with the lack of experience in health science teaching creates a very difficult and stressful transition period. This study contributed to the body of knowledge required to address this problem through investigated perceptions of the health science educators' first five years of teaching and observed 
recommendations that account for faculty member support. The research was accomplished by using a qualitative case study to see if these experiences related to the level of support and preparedness of health science faculty members at WSU.

Understanding the perceptions of the transition to academia is of vital importance in order to remedy this issue and create positive social change. Health science educators are necessary to create practitioners that support the medical field. The implications for social change not only affects the faculty member and the university but also positively affects the health professions as a community by preventing a shortage. The goal, from this research was to capture these perceptions and aid instructors in understanding what is required for them to be fully supported and prepared during their transition period. First, by exploring viewpoints on mentorship, the need for pedagogical training, and professional development recommendations were made for teachers who are currently struggling. Ultimately, for these teachers to embrace these changes by becoming instructional experts and, in turn, helping others. Second, the results of this research could be used by all stakeholders in higher level education internationally as it may lead to teacher preparedness and improved practice guidelines. Stakeholders will view these results as favorable, and have a clearer understanding of the importance of these initiatives for teacher support and instruction and begin to adopt them. Finally, those assigned to provide mentorship will be able to cite trends on instructional best practices and have a profound impact on student learning. 


\section{Research Questions}

The purpose of this study was to examine university health science teachers' perceptions of their first years of teaching. I specifically sought to explore these faculty members' perceptions of their preparedness and the type of support they needed to effectively teach health science-related content and have a successful transition into teaching. I also observed classroom management techniques. This exploration may give a clearer understanding of the importance of these initiatives as they relate to improved practice guidelines. The research questions were

RQ1: How do junior university educators in health science fields at Wayne State University describe their preparations to teach?

RQ2: How does the preparation of teaching intersect with experiences in the classroom for junior instructors in health-related science fields at Wayne State University?

\section{Review of the Literature}

Transitioning from clinical practitioner to faculty member educator in health sciences is a difficult task, especially when new faculty members are not supported, and are expected to perform at a level of their advanced peers. The literature reviewed included articles that discussed issues that new teachers face in their first five years in the field. The study will begin with articles found on the experiences of teaching, standards of university-level effectiveness, junior faculty member support, transition to academia, and professional development. From these sections, social constructivist 
theorists such as Vygotsky (1978) and John Dewey (1897) were reviewed. Malcolm Knowles' (1975) andragogical model of adult learning was explored, to gain knowledge of how to construct our environments and the importance of understanding those academic experiences. Further, Vygotsky's seminal work, Mind in Society, Dewey's (1938) work, Experience and Education, and Knowles' (1975) andragogical model of adult learning provide the conceptual framework and theoretical frameworks for this study. These theories provide a level of understanding that a transition from practitioner to instructor can have on one's development of how we perceive things in our world. Knowles' model of adult learning provides a way to capture something real that is organized and applicable for change.

I obtained the information by conducting a search of the electronic database through Walden University, such as ERIC and Education Source. My database search began with keywords such as faculty preparedness, first years of teaching, and faculty experiences. Other keywords and phrases were used such as why teachers leave, support for new faculty, professional development, and facilitation of mentorship. These articles led me to other articles on the same topic that I have used in my research. I searched books on adult education and qualitative research, which helped me decide on the framework and methodology to use for my capstone project.

\section{Conceptual Framework}

The social constructivist theory explains that the process of inquiry is influenced by the context under study (Lodico, Spaulding, \& Voegtle, 2010). This perspective 
argues that reality is socially constructed and leads to multiple meanings. Different individuals bring different conceptual frameworks to situations based on their experiences, this, in turn, shapes their perceptions of a given situation. Vygotsky's (1978) social constructive model proposed that humans construct sense and meaning from their experiences. Vygotsky (1978) outlined a theory of cognitive development about man and its inner world. The ability of this theoretical framework to apply one's development of perception, attention, and implications on their experiences helps understand the developing faculty member.

John Dewey's (1897) view on social constructivism placed much focus on the subject by understanding the knowledge they create for themselves rather than the lesson they are taught. Conceptually, Dewey delved deeply into what constitutes experience and how that shapes the concept of directionality. Dewey (1938) argued that growth could have an undesirable direction (Dewey, 1938). This perspective helped understand the perceptions one has built through experience and how that can influenced their first years of teaching. This framework is especially important as a researcher to understand the positive and negative impressions a newly transitioned educator faced in academia and provide recommendations based on their experiences.

Bringing together these theories on experiential learning with Malcolm Knowles' (1975) assumptions of adult learning help understand how adults use learner constructed plans to guide their learning experiences. These assumptions are based on the unique characteristics of adults as learners, which form their perceptions. This model builds on 
the conceptual perspective by taking into account societal influences about the translation of theory into practice in a classroom setting. These assumptions will help guide researchers to understanding what tools are needed for teaching effectiveness and what implications these theories can have on overall performance.

This theory, of social constructivism, is evident by the changing views in the facilitation of learning and its multiple aspects of representations of reality. The emphasis placed on teaching students by universities can lead to a lack of preparedness of the new educator (Glaister \& Glaister, 2013). Beginning teachers are expected to perform at a level of their advanced peers and are placed into classroom situations without any organized support (Cherubini, 2007). Additional items that instructors need to prepare for are as unclear expectations, challenging work assignments, and scarce resources create experiences of teaching that are not optimal. By understanding the perceptions that were gathered about the initial teaching experience, research can be collected on the cognitive constructivism that emphasized the nature of learning. From there, recommendations can be made as a supporting tool to ensure instructors are fully prepared during these first years of teaching.

\section{Academic Institutions of Higher Learning}

Starr and DeMartini (2015) reported that understanding and developing teaching practice, when engaged in collaborative inquiry, developed strong teaching pedagogy. Moreover, it appears that exploring the data of whether health science faculty members are prepared could provide strategies for incoming employees to improve support and 
instructional best practice guidelines. Calderwood and Klaf (2014) stated that an institution could provide avenues of opportunities for supporting new faculty members to become experts in all aspects of teaching. Calderwood and Kalf (2014) also consider how the transformative possibilities, of institutional education and learning commons, can influence growth in an educator and enhance the student experience. Each institution has differing requirements that are aligned with their mission (Whitfield \& Hickerson, 2013). It is the responsibility of the university to prepare new faculty members to meet the expectations for their current role for them to fully acclimate to their new environment successfully. Also, certain knowledge is needed to perform adequately within the institution that includes understanding the differences in how the culture creates expectations and values of the university. In a faculty member's new career, institutions of higher learning should assist in preparing the individual for academic life. There are many ways in which this can occur that include, faculty member orientation, mentorship, professional development programs, workshops, and induction programs. If institutions are to lessen faculty member stress and more efficiently support educators, a better understanding of the support they need is required for their development (Saka, Shoutherland, \& Kittleson, 2013). Saka et al. (2013) sought to understand how the identities of faculty members interacted with the teaching context and how this influenced their teaching decisions. Hentges (2012) explored data from authors about possible solutions to ensure preparedness of beginning teachers which include: teaching image, professional development, and mentorship programs. The author provided 
encouraging evidence for educators to remain in the field and addressed implications for positive social change through improved teacher quality and increased student achievement. It is imperative to mention that strong interpersonal relationships in successful teachers have played a significant role in binding individuals to their occupations (Howes \& Goodman-Delahunty, 2015). By understanding the first experiences in teaching, challenges can be dimished which increases the preparedness for newly transitioned faculty members (Barak \& Levenberg, 2016).

\section{Effective Faculty Members}

In a study, Komos (2013) explored the meaning of effective teaching. He discovered that there are many definitions of effective teaching from views of administrators, researchers, and students. University administration considers practical instruction regarding learning outcomes. Educational researchers see effective teaching as the ability to comprehend, reason, and transform. Students are the ultimate observers of education and are asked to score their instructors at the end of each course. Lakin (2015) delved deeper into these categories by establishing criteria for evaluation of effectiveness, which included knowledge of content, a delivery that promotes critical thinking, and student involvement in the learning process. The success of faculty members depends on their teaching efficacy within their instruction (Bedir, 2017). Teaching efficacy occurs through sharing their experience and knowledge through relevant materials conducive to communication (Bedir, 2017). Health science faculty members must stay current in their respective fields, evolve current technologies, and offer new ways to teach material to 
remain effective to create a highly specialized practitioner (Hope, 2015). Individuals cannot do this alone; there must be ways for faculty members to connect using formal and informal ways. With the support of the institution, from their peers, and other collaborative disciplines an individual can grow and remain competent in all aspects of his/her role including teaching, research, and scholarship.

\section{Support for Junior Faculty Members}

Educators of higher learning are content experts and do not necessarily possess the skills necessary to handle the stresses of a classroom setting. Without proper induction programs, universities must find ways to create a more efficient environment for health science faculty members to stay as educators and not go back to clinical practice. Not only does a new faculty member have to deal with being prepared in the classroom, he/she also must identify best teaching practices of these highly specialized health science programs and be involved with research and scholarship . Support is demonstrated with mentorship on career development and scholarly productivity (Fountain \& Newcomer, 2016). Fountain and Newcomer (2016) found that mentors and mentees believe that mentoring is helpful for teaching, research, and planning, which is necessary for success. Mentoring also helps faculty members stay current in their respective fields, which ultimately benefits students (Hope, 2015). If the support for an instructor's pedagogical needs or logical support are not addressed the students suffers the consequences (Guan \& Stanford, 2016). Instructional consultation, via workshops or professional development programs, provides an environment where faculty members are 
supported to design and deliver content geared toward student-centered learning (Kebaetse \& Sims, 2016). Faculty members play a vital role in improving the student's experiences in order to motivate them in their learning process. With that in mind, it is essential that faculty members be supported in their needs to help students achieve their learning goals (Guan \& Stanford, 2016).

\section{First Teaching Experiences}

Despite having exceptional content knowledge, the familiarity with teaching strategies designed to meet the varying needs of students may be underdeveloped when beginning in the professoriate. American educators, of higher learning, have noted that in comparison to K-12 teachers, many university and college professors received minimal or no training in educational theory and methodology (Robinson \& Hope, 2013). Health science faculty members join academia as instructors with clinical expertise. Health science educators have a passion to advance clinical practice which extends their role through laboratory simulations and teaching in the classroom (Burns, Merchant, \& Appelt, 2013). They have little to no formal education about concepts significant to the learning process that can provide many challenges especially in the first years of teaching. Many health science faculty experience a lack of how to teach, what methods to use in a classroom setting, curriculum development, and assessment even for the best clinicians in their first five years of teaching (Burns et al., 2013).

The transition from practitioner to faculty member is not an easy task as the environments and culture differ significantly. This transition is hard due to an already 
achieved level of expertise clinically to the role of novice again. They have worked in a clinical setting and developed the skills necessary to be successful in that environment; however, they must start all over when they reach academia as the focus changes from patient to student with different needs. The ability to maintain the connection, practicality, and identity in the clinical field is a struggle once the move to academia is made (Kniess, Benjamin, \& Boettcher, 2017). Kniess et al. (2017) explored the transition further and have identified that new faculty members experience transitional phases in shifts: the shift to a faculty member mindset, a shift to faculty member identity, and a change in self-perception within the institution. During these shifts, the need for support is essential in order to continue development of new faculty members. Weidman (2013), discussed how clinical experts transition positively when receiving substantial orientation, faculty development, and consistent mentoring as making the transition easier which in turn, creates more competent junior faculty members.

Kumi-Yeboah and James (2012) discussed how teaching experiences take time and dedication to be able to reflect and learn from those encounters. The authors described efficient novice faculty members as those who decide to persevere in the quest to becoming successful and need to pass through many transformational encounters or stages to become experienced. One of these stages is organization and preparation. Organization leads to the acquiring of new skills, building confidence, and implementing effective instructional delivery. Molto (2011) believed that exploring different ways of thinking about those experiences in the classroom with the aim of continued learning 
created a deeper level of understanding teaching practices. Molto (2011) imagined his presence in the course as what he could offer the students with the sense of value and meaning in mind of his professional identity.

Instructors may have a preconceived idea of the qualities of effective teaching having been exposed to this as a student. Interpretations and applications of theory to practice can look very different in different situations such as novice to the expert instructor (Moles, 2014). Moles (2014) stated that if educators use their perspectives in their teaching and challenge their understanding of content this creates equal opportunities for educator's to become empowered and feel a sense of belonging as they once did in the clinical field.

Hu and Smith (2011) explored perspectives of faculty members by exchanging views of their first experiences with teaching and learning to support the practice better. These authors understood the changing environments and expectations students face in the current educational settings in understanding that technology must also be incorporated into curriculum delivery. Novice faculty members in their first years of teaching are very limited in the way they integrate technology into the classroom and may use grade inflation to diminish student complaints and raise teacher evaluation scores (Kimmel \& Fairchild, 2017). Faculty members whose teaching effectiveness is heavily weighted on these scores have added pressure when considering remaining as an educator (Roberts, 2015). If the faculty member's evaluation scores are low, it is the 
responsibility of the department administrator to determine if contract renewal will occur or if a promotion will be gained (Millea \& Grimes, 2002).

Challenges. Novice teachers face challenges such as classroom management, teaching pedagogy, the use of technology, and community involvement (Kumi-Yeboah \& James, 2012). The transition from novice to an experienced faculty member can also provide challenges, as not every faculty member becomes an award-winning instructor. Despite information available to teach scholarly practice, faculty members may be reluctant to move from the primary lecture mode of instruction to other methods due to lack of experience (Briseno-Garzon, Han, Birol, Bates, \& Whitehead, 2016). Classroom practices are rarely shared in higher educational institutions as these institutions rarely collect information about teaching practices (Brizeno-Garzon et al., 2016). As many institutions of higher learning hold faculty members accountable for the student experience by being able to adapt changes while being on the forefront of advances in teaching and learning (Baker, Pifer, \& Lunsford, 2016). Junior health science faculty members have added pressure to the quality of education as it is assessed in the same way a seasoned faculty member is evaluated.

Many of the health science discipline specific programs have small to medium cohorts. Small to medium classes require different skills, sophisticated pedagogy, class activities, and group dynamics (Murray \& Wolf, 2016). Here teaching is adapted toward the needs of the cohort and aligned with student-centered learning at the forefront. This type of teaching and learning create highly developed intellectual skills through 
reasoning and problem-solving. With that in mind, this kind of instruction is one of the most complicated and highly skilled teaching techniques in health science education that must be executed carefully (Shaleh, et al., 2015). With little classroom skills, this is posed as a highly challenging task for success during the first years of the teaching experience.

Many first-year health science professors are challenged by how they are going to apply the designated specific health related theory they learned to create flexible learning environments for students (Zydney, 2014). The skills needed for the student of today are different than they were in the past especially when healthcare and technology are advancing rapidly. With the lack of inexperience may come lack of knowledge transfer. This can affect students when the initial base problem that most health science fields build on may be poorly transferred leading to little retention of material for students (Dinsmore, Baggetta, Doyle, \& Loughlin, 2014).

Preparedness. Attracting allied health professionals to academic settings is necessary for the growth and development of their programs. Universities have tightened up requirements for academia that include having research skills and a masters or doctoral level degree (Clark, Alaca-Van Houten, \& Perea-Ryan, 2010). These individuals that want to pursue education are not prepared for an educational setting. Health science professionals have a feeling of starting over again as their clinical experience did not entirely translate into the classroom setting (McArthur-Rouse, 2008). The lack of preparedness, from this transition to necessary knowledge transfer, can lead new 
academics to go back to the clinical setting (Gourlay, 2011).

Higher educational institutions expect new faculty to be fully equipped to teach (Whitfield \& Hickerson, 2013). The shift for junior faculty members to focus on teaching may lead to a disproportionate amount of time preparing for the lecture, especially if they have other roles such as research and scholarship. Health science faculty members are also expected to teach students through related knowledge, make connections to clinical practice, and present this expertise to a diverse audience (Whitfield \& Hickerson, 2013). With all of the expectations of the university, new faculty members may not even be aware of the understanding of those requirements which can play a toll on their professional and personal life. Understanding the roles in academia such as preparing courses and evaluation of learning is essential to preventing burnout of these demands (Bondoc, 2006). Practitioners have limited knowledge of academic education as many reflect on their experiences with former educators which do not provide any support or information on curricular design or educational theory for today's student (Fain, 2011).

When a master's or doctoral level practitioner enters the field of academia, they are held to the same standard as all other faculty members, regardless of the level of academic preparation (Clark et al., 2010). Many health educators rely on their education and on the job training to help orient them to their new roles. This can create stress as effective teaching is a learned process. Junior faculty members have successfully assimilated to their new environment through faculty development or formal education courses in teaching and mentoring (Clark et al., 2010). 
Within health science programs the existence of both didactic and experiential teaching assignments make the distribution of teaching workload complex. The perception of workload has led to variable job satisfaction (Wilborn et al., 2013). Increased workloads can lead to expanded roles in response to budgetary cuts and increased expectations by administrators (Wilborn et al., 2013). The negative impact of workload can lead to an increased difficulty in fulfilling other duties, besides teaching, such as research and service that can contribute to diminished faculty preparedness. In addition to workload, consideration of personal and professional goals in developing scholarly trajectories leads to the well-being of faculty members (Dunham-Taylor, Moore, McDaniel, \& Walker, 2008). These scholarly trajectories must align with faculty member's balance in work and personal life to achieve success within academia.

\section{The Need for Mentorship and Professional Development}

Andragogy is a learning assumption that was constructed out of adult learner experiences (Knowles, 1975). Therefore, the need for mentorship and professional development should be tailored to the needs of faculty members for retention purposes. In health science, most educator's are clinician experts, so professional development should be geared toward enhancing their transition to academia. The terms mentorship and professional development are used collaboratively to strengthen the experience of individuals in the workplace. Faculty development is defined as the enhancement of faculty members based on the goals and vision of the institution (Bigbee et al., 2016). 
In analyzing the need for professional development programs, Slimmer (2012) addressed objectives relative to health science faculty members improvement: to encourage the development of teaching practices, facilitate the transition from the role of the clinician to academia, and support the implementation of evidence-based teaching practices. Calderwood and Klaf (2014) discussed the importance of supporting faculty members to build a strong foundation for their success in the professoriate. The authors related the importance of learning theory, student learning, and service. The need for faculty development provided opportunities for growth of junior faculty members. Faculty learning communities and developmental programs are rooted in the works of John Dewey who supported the idea of a shared, practical learning (Medina, Tomsek, \& Bowers-Pippin, 2015). The opportunities that programs like this would provide include active engagement, collaboration, and self-directed exploration with senior faculty members about teaching and learning (Medina et al., 2015).

Health science faculty members, without formal educational instruction, can benefit from programs geared toward the department or for the individual through mentorship programs. These programs must foster an academic culture while respecting the professional development needs of the faculty member. To be successful the programs must be supported by the institution, the mentor or program lead must be an experienced educator who is confident and has a passion for guiding others, and that mentees have timely access to the mentor or program to improve their skills (Slimmer, 2012). Scott, Lemus, Knotts, \& Oh, (2016), found that mentorship or professional 
development start at faculty orientation. Through orientation and continued mentorship new faculty members can develop their organizational identity in regards to values and expectations. Individuals are introduced to the resources for faculty members, expectations about teaching, service, and research. The initial presentation to a university will set the tone for how a new faculty member will contribute and engage within their new environment.

\section{Implications}

In the interest of creating a prepared instructor that is effective in teaching practice may help support a successful transition for a junior faculty member. A researcher must explore the influences affecting the transition of junior faculty members to academia to understand what kind of support these individuals need for their

development (Saka, Shoutherland, \& Kittleson, 2013). With the assistance of mentorship or professional development programs, a newly transitioned faculty member can feel prepared which is essential to one's teaching practices. Once this is established the support needed to enhance their practices, and ultimately the student experience will encourage faculty members to thrive at the academic institution.

\section{Summary}

Exploring the perceptions of the first five years health science faculty members creates an understanding of what is needed for junior faculty member support. The need for pedagogical training of faculty members, the student experience, and the need for faculty professional development programs will play a vital role and support in their 
successful transition from the clinical setting to academia. Section 1 of this study includes the problem, provided the research questions and key terms, and reviewed the pertinent literature. Section 2 of this study, the components of a qualitative case study are explained to complete this research. Interviews and observations were conducted and exit interviews examined for complete data collection. The data analysis will also be reviewed and described. 


\section{Section 2: Methodology}

\section{Introduction}

Health science practitioners have an established knowledge of the clinical setting. Many practitioners who transition to an academic institution have little to no training in educational methodology and theory, however (Robinson \& Hope, 2013). Upon obtaining a master's level or doctoral level degree in their respective field, they are considered qualified to teach at WSU, the project site. Adapting and managing a classroom in addition to keeping up with advances in teaching and learning can lead to a novice faculty member being unprepared (Baker et al., 2016).

The goal of this study was to examine university health science teachers' perceptions in their first 5 years of teaching. Specifically, I sought to examine the perceptions of preparedness of these newly transitioned faculty members, identify perceptions of the type of support needed, and observe classroom management techniques to be able to teach effectively. In this section, I describe my role and the role of the participants chosen for this study, along with the criteria used for participant selection. After doing so, I discussed the setting of the study. This discussion is followed by an overview of the data collection and analysis procedures. The credibility of study data is also addressed.

\section{Research Design and Approach}

I chose a qualitative case-study approach to gain an understanding of health science educators' perceptions about their transition from a clinical setting to academia 
during their first 5 years of teaching. According to Bogdan and Biklen (2007), qualitative researchers are "concerned with understanding the behavior from the informant's frame of reference" (p. 2). Similarly, Merriam (2012) described the central characteristics of a qualitative case study as an in-depth exploration of one's experiences. Furthermore, a case study is the choice of when studying given boundaries (Merriam, 2012). The use of interviews and observation allowed me to engage in a rich exploration of the study phenomenon. Regarding design, a case-study approach fit this research because the design involved detailed examinations of particular subjects (Bogdan \& Biklen, 2007) and is based on constructivist paradigm. As Starman (2013) noted, the use of a case-study design allows a researcher to examine the experiences of individual cases (here, health science educators that have transitioned from a clinical setting to academia) in detail. By performing a case study, I was able to explore in depth participants' perceptions about the transition from clinical practitioner to academic.

Stake (1995) described explanatory case studies as a method of investigating a given phenomenon. The qualitative case-study type best suited for this study was explanatory. My aim was to understand a particular case or individual to learn more about the transition to teaching. In this study, perceptions of health science university faculty members in the first years of teaching were reviewed. I explored whether these perceptions relate to unpreparedness during this period and offered recommendations to better support the transition. The choice of case-study must align with the purpose of the study (Merriam, 2012); the explanatory design was appropriate for this research, I 
determined. An explanatory approach is used to explain the causal links in real-life situations that are too complicated for experimental strategies (Yin, 2003). This approach gives the researcher the ability to describe an individual's perception about transitioning to academia in a way that is not with experiments.

I determined that other research designs for qualitative data collection such as ethnography, phenomenology, narrative study, and grounded theory were not appropriate for this study. Ethnography is a strategy of inquiry that is used to investigate an intact cultural group (Creswell, 2012). Because particular cultural backgrounds were not reviewed, this was not an appropriate design. I chose participants based on their educational, not cultural, background. Phenomenology was not suitable because there was no attempt to understand the meaning of events, in particular, situations, whereas the attention is not paid to the individuals (Bogdan \& Biklen, 2007). Narrative inquiry design was not appropriate for this study as there was no attempt to ask junior instructors to provide stories about their lives; this was a study focused solely on the transition to academia and on determining if a relationship exists during this time to lack of preparedness and support. Grounded theory design was not suitable because there was no abstraction of a theory about the process of novice faculty member perceptions (Merriam, 2012).

A quantitative study was not appropriate for this project study because the data collected during the interview process was not specific nor numerically measurable. This data allowed full exploration of one's perceptions of their first years in the teaching 
profession. The sample size was intentionally small because contacting and interviewing all novice professors at this university would have been difficult. Another reason why I opted against using a quantitative approach was because this study did not fit the quantitative model for generalization. The results of this study will help provide guidance on the ways to support novice faculty members instead of a standard and fixed set of result data, as seen in quantitative research (Creswell, 2012).

My justification for using a case-study qualitative approach is supported by Bogdan and Biklen (2007), Creswell (2012), and Merriam (2012). According to these researchers, qualitative researchers are allowed to explore variables and present detailed findings. I used a case-study design to gain an in-depth understanding of health science faculty members' perceptions about their first years of teaching. I conducted interviews to ascertain the participants' feelings, perceptions, and ideas about the topic being studied. In addition, I observed participants in the classroom. Lodico et al. (2010) described obtaining a fuller representation of teacher participants' preparedness and support by considering their behavior and the conditions of the natural classroom setting. By combining observation and interview information, I surmised that there would be enough data to gather and produce rich descriptions in order to justify their views.

The purpose of this study was to explore the perceptions of educators at WSU about the sufficiency of their own preparedness and support needed to teach in health science programs. I used a constructivist theory of learning, from Vygotsky (1978), to guide the study. Specifically, I sought to understand if these experiences contribute to the 
problem of the lack of preparedness and support of faculty members at this higher education institution.

\section{Participants}

Purposeful sampling techniques of various current health science related faculty members within their first 5 years of teaching at WSU were utilized. Access to the participants was gained via the deans of these departments. Purposeful sampling should reflect the situation or phenomenon of interest of the average person (Creswell, 2012). The intention was to explore faculty members' perceptions and experiences with teaching once transitioning from clinical setting to academia through interviews with chosen participants. Participants selected were WSU faculty members from health science related fields within their first five years of teaching. It is important to attract allied health professionals to academic settings for the growth and development of their programs as it positively affects the health professions as a community to prevent a shortage.

\section{Ethical Protection}

Before the study, approval from the Institutional Review Board (IRB) at Walden and Wayne State University's was gained to ensure the protection of human subjects using Walden's standard IRB template application. The protection of these participants was gained by explaining that the data, for this study, will be kept confidential and not shared with their program directors or deans until the member check process is complete. Pseudonyms for participants pseudonyms was assigned to protect their identities in the final report for any documentation related to this study. Each participant was given a 
clear explanation of the study and necessary privacy protection. Study details such as the description of procedures, protection of confidentiality of participants, the role of the researcher, and interview protocol was submitted to the IRB for review and approval (Creswell, 2012). Participants were asked to sign an informed consent document that covers why this information is captured and how it will be used.

\section{Access to the Participants}

Access to the participants of this study was gained, via the researcher contacting the participants directly through email, after obtaining permission from the deans of health sciences. The deans of health sciences provided a list of health science faculty members in their first five years of teaching. After permission was granted from the deans of health sciences and the list of faculty members is obtained, the researcher contacted each prospective participant via email. Once the participant ensured acceptance, another email was sent to arrange an interview and a direct observation time.

Since there are nine programs within the health-related fields at WSU, a sample of faculty members, were interviewed, until saturation was met via overlapping themes. Since the participants are from one university, all come from a transitioned clinical setting to academia within five years, and teach health related programs, saturation level was met with fewer participants. All health science related faculty members participants were purposefully selected from the criteria mentioned. Approval from Walden and Wayne State University's IRB was sought before attempting to contact any of these individuals. A letter to the deans of health science was created that outlined my 
educational background and purpose of the study (see Appendix A). Permission, from the deans, was required to review exit interviews from former health science teachers leaving academia within their first five years of teaching as a way to better understand the purpose of their intent to leave. I offered a follow up meeting with the deans to address any concerns or inquiries they had about the study at hand before contacting any participants.

Once the deans of health sciences granted permission, I emailed each prospective participant describing the purpose of the study, the criteria used for participating, and explain the interview process. Once the participants agreed to the study, a copy of the consent form and letter of confidentiality was discussed. Each participant will took part in a 60 to 90-minute interview regarding their perceptions about their transition from the clinical setting to academia within their first five years of teaching that allowed time for a question and answer period. Each participant also allowed me to directly observe their classroom teaching process as a way to obtain a fuller representation of preparedness and support in the classroom environment. I provided my personal contact information in order to set up interviews and direct observations.

It is of utmost importance that the participants are protected from any unintentional harm or impairment of their professional performance. After scheduling the interviews and direct observations, I explained that participation in this study is strictly voluntary and that they can withdrawal at any time. Informed consent was attained which described in detail the purpose of collecting the information. I explained that they will not 
receive any stipend, gift or reward for their participation. I also ensured that the participants understood that the collected data that will be kept confidential, and not shared with their program directors or deans. I also assigned them pseudonyms to protect their identities in the final report for any documentation related to this study. All of these measures were taken to ensure confidentiality and minimize any risks to the participant.

\section{Data Collection}

Data for this project study came from interviews and observations from current novice health science faculty members and exit interviews from former novice health science faculty members. The data collection instruments used, in this study, set the boundaries for this type of qualitative research by exploring multiple forms of inquiry to gain a deeper understanding of the natural setting and situation (Creswell, 2012). The data instruments included interview, observation and an exploration of exit interview documents that expanded the knowledge required to serve the research questions at hand. This collection of supporting evidence was based on recurring themes discovered by noting repetitive words during document analysis. The main focus of this study was to gather information about the sufficiency of their own preparedness and support needed to teach in health science programs.

\section{Interviews}

A collection of data for this research study utilized a one-on-one semi-structured inductive heuristic interview based on the research questions posed. Based on Creswell's (2012) types of questions, the semi-structured nature will include experiences, 
perceptions, knowledge, and opinion questions. Merriam (2012) described a semistructured interview as a guide that enhances flexibility with a list of questions or issues to be explored. This structure provided the flexibility, as in an inductive heuristic approach, to discovery that is sufficient to meet the immediate goals of the interview. Recommendations for best practices in higher education teaching and learning from the National Education Association (NEA) 2017 were used to develop the context and focus of the interview questions for all participants (see Appendix B). Consent from participants was obtained before each participant was interviewed for approximately 60 to 90 minutes using an interview protocol. A sample of faculty members were interviewed until saturation was met by reviewing overlapping themes and when the information that was received from participants seemed to repeat general terms and perceptions. The interview was scheduled at the participant's or researcher's office at a time that was convenient for the participant. Audiotapes were produced to be able to review and translate themes using recurring words and patterns into a cohesive written document. Written field notes were taken during the interview process to gain a better understanding of the information provided and correlate those notes to the audiotaped transcripts. A follow-up meeting was arranged to review the interview transcriptions as a way to perform member checking. Each participant reviewed the transcribed interviews to ensure that what was said during the interview is what they were intending on portraying about their perceptions of the first years of teaching. 


\section{Observation}

Another method of data collection was to observe each instructor's classroom setting, multiple times, in the role of nonparticipant observer. The rationale for these observations was to obtain a fuller representation of their level of preparedness and support by considering behavior and conditions of the natural classroom setting of the participant. According to Merriam (2012), observations "represent a firsthand encounter with the phenomenon of interest rather than a secondhand account of the world obtained through an interview" (p. 137). An introduction was made to the students as to the purpose of the observation, then a portion of three separate 90 -minute lectures was observed unobtrusively at the back of the classroom when students are present during a typical lecture. The observations were scheduled at the participant's convenience and location. During this time, field notes were written and permission, from the instructor, was granted to record the classroom interactions. Follow-up interviews with the lecturer was performed soon after the lesson to describe their perceptions of the classroom setting on what I observed.

The literature review provided the context for the creation of the observation field notes form for this study (see Appendix C). Additionally, the Glaister and Glaister work (2013) on the standards of university teaching described the standards that are expected

of a competent university instructor and were used as a guide for observing preparedness and support as related to this study. These standards include a demonstration of subject knowledge, preparation of lecture, delivery of lecture, and interaction with students. For 
this study, the researcher observed the prevalence of expectations to inform what strategies novice instructors can use to help classroom management and assist in preparation. The recommendations of Glaister and Glaister (2013), on the standards of university teaching that coordinate with the observable competencies, which include motivating students, demonstrating excellent subject knowledge, and delivering wellstructured sessions.

\section{Documents}

The final method of data collection was to analyze any exit interviews from former health science faculty members for reasons why they left the university. These documents were requested through the deans of health science on former health science employees. The portion of these exit interviews that is worthy of exploration is the reason for departure as this pertains to this study. To protect the individual all documents for review were screened by the deans. Only portions related to the study were available to the researcher and all other portions excluded including employee name. The purpose of using documents, as part of the data collection process is to determine as much as possible about the phenomenon you study (Merriam, 2012). This information helped achieve a broader perspective of the results of teacher preparedness and enhancing faculty member support for active junior and future health science faculty members. This collection of supporting evidence was based on any recurring themes discovered by noting repetitive words during document analysis. 


\section{Role of the Researcher}

My role as a researcher in this study was to select active junior health science participants within their first five years of teaching, obtain permission, conduct the interviews, complete observations in the classroom setting, analyze exit interview documents, collect and analyze the information provided, and discuss the results with the participants. During this study, I was be a full-time faculty member of the clinical laboratory science program at WSU; however, I had no jurisdiction over any of the participants of this study nor is a supervisor, colleague, or mentor of any participant. I was not being paid by any departments of the university and does not know any of the members on a personal level. It is of utmost importance that the information was not released to any possible health related chair or dean as this may have negative implications for the participant's employment and may interfere with the data gathered by exposing the participant(s).

It is the role of the researcher to select participants within the health science field in their first five years of teaching. Any data, recording, and analyses are the responsibility of the researcher. There was no outside researchers participating in any phase of this study. Although the researcher is a university professor at this institution, none of the participants belonged to the researcher's department, and none of the researcher's students participated in this study. A minimal level of bias may have been present in this study because of the criteria listed above. The ways in which I minimized researcher bias was to review the commitments to confidentiality, review the data 
methodology in detail to not stray away from the focus of the study, and keep detailed records.

\section{Data Analysis}

Merriam (2012) described qualitative data analysis as a dynamic process that becomes more intense as the study progresses. The ultimate goal was to make sense out of the data collected. Reviewing, transcribing and creating themes can ensure the focus of the study remains intact. The data analyzed for this study was interview recordings, observations and field notes, and exit interview documents.

\section{Interview Analysis}

An inductive heuristic approach to reveal relevant information about the study was performed on the interview transcripts (Lincoln \& Guba, 1985). This method used reasoning to supply substantial evidence based on the information given by the participants. It suits this study, as the conclusions analyzed were built on the participants' current knowledge and experiences of the first years of teaching, which related to the purpose of the study. This approach also provided the flexibility to discovery that is sufficient to meet the immediate goals of the interview. The researcher transcribed the entirety of the audiotaped interviews including pauses and silences. These transcriptions, with the observational field notes, were compared using recurring regularities using a coding process. The information gathered was broken down based on the recurring regularities of the questions composed for the semi-structured interview on experiences, perceptions, knowledge, and opinions. These categories were placed into a coding 
process. The coding process included focusing on patterns and insights related to the purpose of this study and marking main themes related to the conversations recorded (Merriam, 2012). During the first level of coding, observations for distinct concepts based on the interview questions were formed based on the analyses. By re-reading the interview transcripts after the first level of coding, exploration of how the concepts were related to the observation were noted, and its associated effects of consequences were examined until saturation of information was met.

\section{Observation Analysis}

The observation field notes forms were compared for the determination of recurring occurrences and patterns of identified expected standards of university teaching across the health science participants of the study that coordinate with the observable competencies which include motivating students, demonstrating subject knowledge, and delivering well-structured sessions. Additionally, the observations were compared to the coordinating interview transcripts of the participants and the standards expected of a competent university instructor for observing preparedness and support. The purpose of analyzing observational and interview transcripts was to identify any related concepts that applied to the perceptions of the participant that delineated what they stated in the interview process is what is being demonstrated in practice.

\section{Document Analysis}

Exit interviews were requested on former health science faculty members for reasons why they left the university to help enhance active participant support; however, 
they were not available. The exit interview documents would have been analyzed to identify specific themes related to preparedness and support of individuals during their employment with the university. Themes would have been deemed by reading these documents then noting down the use of repetitive words. Repetitive words would have indicated that these descriptions were important to why they decided to leave academia. These materials could have supported the plans that were used to provide recommendations for professional development or mentorship programs to ensure faculty preparedness and support.

\section{Data Results from Interviews and Observations}

Interview Question 1: Can you tell me your clinical background? How many years have you been in the clinical field prior to pursuing a career in academia? What ranks in the clinical setting have you attained? Each of the eight participants interviewed had a minimum of a Master's degree, and all belonged to an affiliated WSU healthcare program. All of the pharmacy participants and nurse anesthetist had doctorates in their respective fields. A lack of these advanced degrees by the other participants is most likely due to the availability of these doctoral programs within their fields at this university. As for pathologist's assistant and mortuary science, there are no doctoral options within their field and these participants have a Master's in Business and Linguistics respectively as their programs are undergraduate level. Besides the pharmacy participants, each of them has worked in their respective field for at least three years to a maximum of 30 years in a healthcare setting. Their roles were solely based on clinical settings in which they were 
trained; therefore, come with a wealth of clinical experience. The pharmacy participants have completed a 2-year pharmaceutical residency, which prepared them for the clinical setting as well as academia. The expectations of teaching to service to scholarship workload ratios vary significantly between each program, although each job title is assistant clinical professor for WSU. Teaching workload ratios ranged between $40 \%$ - to $90 \%$ between programs.

Interview Question 2: Why did you decide to transition to academia? All eight of the participants pursued academia for positive reasons. They all wanted to explore teaching as a career, and to re-invest their time and efforts into the next generation of students. They were all very ambitious women and were encouraged that academia provided a wide range of roles that expanded them professionally. One participant noted that "she enjoyed teaching at the students level." Besides, being in academia gave them the opportunity to be lifelong learners who are devoted to the evidence. They all liked the fact that they will be partaking in research, particularly, quality improvement, educational research and health outcomes that affect the local community. This community involvement encompasses all the things they portrayed as the perfect job, and they felt delighted about coming to WSU. Although one participant was "unsure of her path" she wanted to explore what academia could offer that the clinical setting could not. However, all of the reasons for transitioning to academia were positive, one participant delved more into why she was looking for another career opportunity. This participant worked in the clinical field for 30 years and felt that advancement opportunities were limited. She felt 
that "this was all I could do" at that particular healthcare setting and wanted to pursue a career where she used her doctorate and stated, "I worked very hard for my degree to not use it." She started to search for another job when the job at WSU became available; she decided to go for the opportunity, listing some of the benefits above.

Interview Question 3: Can you describe, and give examples, of your interaction with the students during your first years of teaching? One participant, in the pharmacy department, is within her first 18 months at WSU. This department has protected time from teaching and is not assigned a course in a classroom setting to get their clinic setting running efficiently before taking on additional responsibilities of teaching and research. Her administration also recommends against volunteering teaching to alleviate stress and additional responsibilities. She did have experience teaching during her residency and felt that she could still contribute to the questions of this study because she has experience teaching in a classroom setting. When asked this question, two of the eight participants told the students that they were new to the field of teaching but gave them their experience and profession background. All eight interviewees felt nervous about the classroom setting; one participant felt like she had imposter syndrome, even though she felt confident in her subject matter knowledge but did not feel expert enough to be teaching. A participant felt like a perfectionist and commented "I tend to over do it, my anxiety was very high even before any student encounter." One participant stated, "what I had to get used to is knowing when to challenge the student, when to make exceptions, when to be lenient, but most of all be consistent." When asked, all participants felt that 
they had good participation from students, and thought they were engaged. All participants seemed to care about their students by trying to communicate with them by using discussion, via WSU learning management software, trying to put the students first. Another participant told the students that they were new to teaching and stated: "as long as we act professionally toward each other we will all meet our goals, this is an experimental approach please be flexible with me."

Interview Question 4: When you began teaching, in what areas did you feel you were the most prepared? (content, classroom management, course design, communicating with students)? Why do you feel that you were so prepared for these things? All eight participants felt the most comfortable with the content of the material. One participant not only felt satisfied with the content but also the delivery of the material. She claimed that the teaching certificate, provided through the residency, helped her become ready to give a lecture. This participant stated, "because I was taught by former faculty members on how to teach, I only included what was important for them and ensured they got the basic information from my lessons." They felt this way because they were teaching what they had learned from clinical practice. Since they had experience in their respective fields, they felt that they had the ability to break down the information into key points. They also thought they could use the lecture material to correlate current professional practices. In addition to lecture preparation one participant enhanced lecture preparation by including basic steps in her lecture notes such as "change slide" or "point to upper arm." 
An essential way in which they felt most prepared was by giving students pertinent information that was necessary for them at the stage they were as students.

Interview Question 5: When you began teaching, in what areas were you the least prepared? (content, classroom management, course design, communicating with students)? Why do you feel that you were least prepared for these things? Provide examples? Support, mentor? The answers to this question were shared among the eight participants. They stated that they were not prepared for the unknown meaning they were not prepared for what students were going to ask them, navigating WSU or they were unaware of the expectations of them by their administration. Although one participant was given lecture notes for the class, she stated she was not ready for the classroom setting. This participant commented "I blithely believed that I could pick up right where he left off. I was sadly mistaken. I was informed by my students in their course evaluations that I was the worst teacher they'd ever had." Three participants were unsure if students would go beyond the instructor's scope of knowledge and ask questions that they could not answer yet. They all want to be seen as respectable and knowledgeable leaders but being new means that their confidence is not where it should be at this point in the transition. Three participants also felt unprepared on how to create rubrics, navigate evaluation, marking for consistency, and assessment of students. One participant stated that she "had not even heard of a rubric until a student inquired about it." One participant stated how difficult it was to "create objectives with standards to follow." Another participant noted that the grading scale at WSU was "subjective; there was a lot 
of academic freedom, which meant a lot of room for interpretation and people's views on remediation." There was no policy on accommodations nor plans for remediation from the College of Health Sciences. Lastly, two participants had difficulty navigating the learning management software, Blackboard; they did not know the technical skills and were lacking the resources to set their course up by themselves. Both participants sought assistance from information services.

Interview Question 6: In what ways do you feel that your first years of teaching experience could have improved or changed to better prepare you in this transition? Provide examples? Four of the participants could have improved this transition by taking steps necessary to handle students challenging questions. Each participant expressed a need to have the authority and confidence in the classroom without getting "flustered" by its setting and environment. All participants also noted that if they were fully prepared as they were after a year's time in academia than their anxiety about the unknown would have been less. One participant has commented about preparation "times change, students change, and education must change as well." Three of the participants would have liked to limit themselves to what could happen in current practice, opposed to when they were residents by identifying what they need to know and not confuse them, provide these students the proper stepping-stones of learning. One significant comment that one participant stated was that she "could have improved by taking steps that would have prepared me to clarify what the student's expectations were from me on day one." Both the student and instructor must understand what was expected of them and discuss any 
changes to make a partnership. One participant did not discuss these expectations and made changes during the course about writing assignments; "this was not well received by the students." She now can plan and organize her semester better now that she is aware of the time commitment needed by her to complete each of the writing assignments that is feasible to be successful and give timely feedback. All of these participants were new to teaching university-level students. They all mentioned in a summarized way that they needed to get timing down for classroom work, as the participants wither went over or under the scheduled lecture time. Since these participants enjoyed the material they were teaching because they were fully invested in doing a good job and were passionate about it. One participant mentioned practicing lecture ahead of time to get the proper time management mastered to move into lab. This final quote sums up the entirety of this section: "I think the biggest challenge to new teachers is being unconsciously incompetent, they don't know what they don't know. When I walked into that classroom the first time, I had no idea what I was getting into. I would love to see some job shadowing or teaching assistant positions available to new teachers."

Interview Question 7: Can you describe your experience and knowledge with the content you were given to teach? Can you provide examples? Although all participants knew at least two months in advance what they would be teaching, they had different experiences. Four participants had a chance to look back on past lectures of the same subject for material and guidance. These four participants had time to see what to improve, by making sure the information was current. It was beneficial that the material 
was given to these participants as a guideline to transition to academia. One participant stated "it gave me time to review the lectures, improve it by making it current." These individuals also had mentors who have taught these same classes, and they discussed the lecture material to ensure they were ready to teach. Three of these four individuals only had one class to teach their first year and had plenty of time to prepare, while the fourth participant just had the one class to teach her first semester. The other four participants had one to four courses to teach their first semester of transitioning to academia. None of these four participants had an assigned mentor that could assist them with the preparation of the classroom setting nor the content to be presented. One participant stated that "I watched hours of YouTube videos of lectures and took reams of notes to use in my classes to prepare." There was no guidance from the administration on the act of teaching nor how to create subject content and deliver it successfully. These four participants had to learn the timing of a lecture and how to use activity for full student benefit. This stressful period lead to "a lot of crying", for one individual, in the beginning, but lead to overall persistence. One participant was sick often with shingles and high anxiety. These four participants all decided to gain more knowledge by teaching themselves "how learning works" to understand the student's perspective that is current and relevant. They also learned course development and sought out as many resources as were available to them on their own. One of these four participants found a peer in another program that offered guidance and assistance with teaching and gave her emotional support. 
Interview Question 8: Do you have any training in instructional methodology? Were you confident in teaching the subject matters content? If not, why not? Three of the pharmacy participants, through their residency, achieved a teaching certificate. The teaching certificate was a program that was offered to pharmacy residents by their pharmacy programs. There was a specific agenda as to what it entailed. There were reading, assignments, teaching portfolio, teaching philosophy, discussion facilitator, and creating lectures. One pharmacy participant felt it helped her "prepare and get ready for teaching in a classroom setting." It gave them small and large classroom experience with a lecture that has layered learning. The pharmacy participants were prepared in this residency to teach others and to teach in the medical school. No other participant took any formal course or courses in educational or instructional methodology or technology. One non-pharmacy participant stated, “does YouTube count?” Although some participants experienced formal instructional methodology some participants found their own means of informing themselves on how to prepare for a classroom setting and course design.

Interview Question 9: Have you had any experience with course design or management? Was there support within the institution to help in your transition with course management and design? Three of the pharmacy participants, through their residency, had experience with course design and management through their residencyteaching certificate. The experience in this certificate for course design offered the creation of a lecture, syllabus, and rubrics. They had many opportunities to teach within 
their program and outside their program to ensure the material they created was clear. One pharmacy participant felt it "helped prepare and get me ready for teaching in a classroom setting." The pharmacy participants were prepared in this residency to teach others and to teach in the medical school. No other participant took any formal course or courses in course design or management.

Interview Question 10: In what ways has the institution supported you as you began your teaching career? (administration, workshops, orientation). Provide examples? Participants noted that they received institution support from the College of Pharmacy and the Office for Teaching and Learning. The College of Pharmacy administration supported sending the pharmacy participants to conferences each year to encourage new faculty to receive information that would help new instructors prepare for their career in academia. There is also support from the administration about going to a team-based learning conference as this is supporting best practice in the field of teaching. The Office of Teaching and Learning was supportive by offering workshops on using the learning management software of this university, it's efficiently, and creating proper exam questions. Four participants feel that the administration fully supports and helps encourage new faculty to be prepared. One participant stated she sat down with her program administrator every two weeks for an hour for the first semester she transitioned. They discussed who to talk to for tech support, course design and answered all of the questions she had as a new faculty member. Four of these participants also had peer mentor support from a fellow full-time colleague within their programs. They discussed 
how to set up an exam online and talked about the "ins and outs" of the college. Three of the participants feel that the university is trying; they have created an onboarding process, which includes a checklist the chair gives to new faculty. They have to find people on the list and introduce themselves. One participant has only met with the department chair, administrative assistant, computer and information person, and student affairs once. This checklist was not given to her when she started, she asked for some guidance a few months after starting, and a meeting was arranged with the chair, and this checklist was given to her. This participant still has to meet with her program director about this form because it provided no telephone numbers or email addresses on how to get a hold of these individuals on the list. She feels like "the checklist was not useful if it is not explained and felt very discouraged." Two participants have not even seen any documents or checklist to fulfill and had to navigate their initiation themselves. One participant noted, "The university is trying" to assist faculty and "maybe they are not sure what areas are lacking to support faculty". The office of Teaching and Learning is the beginning for supporting faculty.

Interview Question 11: What advice would you give to current novice faculty members that you feel would benefit them when they are hired in academia? The following statement on the positivity of teaching was recorded by one-participant "seize opportunities that best promote you and a friendly teaching environment." Comments about having positive relationships within their departments and its importance included: "reach out to your fellow faculty, and program director for support and advice, there is 
always someone here to help" and "maintain a good relationship with your department chair so you know expectations for promotion early on in your career.” The following statement recognizes how hard this profession is and provides positive reinforcement: "the beginning is very stressful, and it will take time, be patient with yourself as you will have to make it work," "teaching is harder than you think. Get familiar with the curriculum, content, outcomes, accreditation standards and rubrics", and "teaching is harder than you think. Keep up with changes especially if your program is accredited." The last section of advice includes the academic environment: "be okay with that lull that first happens when you come in and don't feel this drive to like jump into everything at once, then you will get overwhelmed" and "environments may be different in each department, gage yours and ensure that you are self-motivated enough to help yourself be successful at your job. Hard work pays off."

Interview Question 12: Can you add any other information that you feel would be helpful for future clinical practitioners moving to academia so they are prepared and supported in their first five years of teaching? The following comment discusses selfpromotion and how to be your own advocate to become successful in academia "I was never told what my expectations were nor given any weight on how to achieve scholarship, service and teaching proportions. Find out what your expectations are so you can be fully prepared." One participant wanted to ensure new faculty members are aware of the challenges faced: "I think the biggest challenge to new teachers is being unconsciously incompetent, they don't know what they don't know. When I walked into 
that classroom the first time, I had no idea what I was getting into. I would love to see some job shadowing or teaching assistant positions available to new teachers." One participant wanted to give new faculty a sense of importance: "when you have a small undergraduate program, the services are lacking for mentorship and induction. It is very hard to recruit for undergraduate programs that do not offer a masters level program when you are required to have an advanced degree to teach. That is why you need strong support from the administration to help the transition." Finally, one last piece of additional information: "Say NO to added responsibility. You have to advocate for yourself" and "if you decide that you love this profession, make sure you like teaching and are comfortable adjusting to taking on more than you are an expert in."

Observation analysis: Observations were completed on three out of the eight participants. The larger health science program participants do not teach classes during the spring and summer semester; therefore, I was unable to view their classroom practice. Over a period of six weeks, the participants provided me with times when they wanted me to view their classes. Approximately one hour of multiple sessions of the other participant's classroom teaching was observed. The courses observed ranged from science related to research methods. Each classroom was set with the instructor at the front of a small lecture hall with a projector displaying their PowerPoint lecture. All of the students are facing the instructor. Most of the students have their own laptops, are viewing the lecture, and are following along with the instructor or they have printed the PowerPoint slides and are making notes by hand. Each program has a cohort of students 
ranging in class size from 12-40. Each classroom displayed a dimly lit modern room with excellent technology. All of the participants observed seemed to have a positive relationship with the students. One participant asked a student about their personal life before lecture begins. All students for all participants seemed to be paying attention when lecture begins. Two of the participants began with a review of previously learned material. These instructors used ways to get students to remember the material easily by providing them with acronyms. These instructors have expanded on the teaching by using relevant examples that were used as definitions. All of the participants seemed very knowledgeable with the content. All participants have taught in a classroom setting at WSU except one participant. This is her first class at WSU, before the class began this participant is struggling with the sound technology of the classroom. She intended to use a pre-recorded video to demonstrate a more in depth knowledge of content. This is the first time teaching this course and it is obvious she was not completely comfortable. She provides information based on simple PowerPoint, which has some images, and writing. She is reading the definitions from the slides; however, she used examples from clinical practice to expand their learning. The instructor seemed somewhat comfortable with the subject content. This is the only participant where nervousness was observed. She had to build this course without support from other faculty members and it is not as polished as the other participants observed were. The other instructors expanded on their teaching by using relevant examples that are used for definitions. One participant used a fill in the blank sheet as a working document during lecture presentation. She uses the answers as a 
way for students to respond and as a review. All instructors had a friendly, calming voice. I do not sense any nervousness or stress demonstrated by any other instructor. I did not observe any participant getting emotional or disappointed when a student answered a question wrong rather I observed them re-direct and help the students answer the question with hints. After 20 minutes some students, from all participants, have stopped following along with lecture and are exploring the internet or talking quietly to each other.

From the interviews and observations, I have derived the following common themes: (a) peer mentoring (b) administration support (c) institutional support (d) interaction with students (e) instruction methodology and educational technology training

\section{Discrepant Cases}

Although the final method of data collection was to analyze any exit interviews from former health science faculty members for reasons why they left the university they were not available. These documents were requested through the dean of health science on former health science employees. The correspondence via the dean stated that "the exit interview is available, but many faculty do not opt to complete them. I have not been given access to any of the exit interviews." She instructed me to contact the regional director of human resources for the College of Health Sciences. The correspondence from the human resources manager stated, "Currently completing an exit interview is optional and there isn't a process to collect and report out to information collected." No further correspondence has been pursued. 


\section{Data Analysis Results}

All of the participants had clinical experience and were all very ambitious individuals. They transitioned to academia for a chance to grow professionally in a wide range of roles. These eight participants had varying degrees of perceptions about their first years of teaching that helped or hindered their preparation to teach. The interviews showed that the transition to academia is easier when there is support by the institution, administration and peers. The observations showed that these participants wanted the student to succeed and a positive relationship ensued. These combined documents provide the themes created above about the perceptions of teaching preparedness.

I derived the results from this qualitative case study by interviewing the participants and observing their classroom teaching. Interviews took place individually in their respective offices and recorded. Observations took place in the participants' classroom.

\section{Themes}

The following themes were derived from the analysis.

Theme 1: Peer Mentoring. The four participants that were assigned a mentor stated that they did not have much stress due to having colleague support. These mentors helped guide these individuals by discussing the university and its students, giving them teaching material, and explaining how to teach. They also stated that their mentors talked with them about their transition to academia and held regular meetings for clarification and advice on what to expect. One participant said how crucial it was that she was paired 
with an individual that "met my needs and an individual that I already had a positive relationship with." This positively assigned mentor had also taught the same class, which provided an opportunity to pass over already created lecture material. To provide even more support for teaching preparation, this faculty member mentor had discussions about the lecture material with the participant to ensure she was ready to teach it. The importance of being assigned a positive mentor that aligns with your goals is vital to the success of the faculty member. While four participants had a positive experience with mentorship, four other participants experienced a negative mentor relationship or no mentoring relationship at all. One participant was assigned a mentor after months of being in her current position. This participant did not feel that this information was helpful, as this mentor did not have the same philosophies at this point in her career and he "only talked about his accomplishments." She felt the meetings were inconsistent and the initiation to continue meeting was put onto the new instructor to arrange more meetings. They were set up as a reactive mentorship, not proactive, to ensure acclamation is successful. This participant stated that she cried a lot during her first year. Another participant was assigned a mentor; however, this mentor called her once, and 'didn't know the field because he came from another discipline" nor could provide her any useful information about her program. She thought the relationship was not a good fit after the initial phone conversation. This mentor did not reach out again, so she asked different program's faculty members for advice when she met them. Two participants were not assigned a mentor at all. However, one participant had a near mentor group 
relationship as her meeting with her chair, months after starting, discussed the possibility. Her administrator asked if she was interested in having a mentor, she stated: "of course." The administrator at this time told her that she would send out an email for her to join a mentor group. The particular mentor group meets twice a year. By the time, she would have been eligible to join this mentor group her first year of teaching would have been completed, including teaching two courses. One participant was not assigned a mentor nor was there discussion of a possible mentor relationship. She commented, "I had to learn the names of a lot of faculty and assistants in my program on my own as well as take a tour of the building." The two participants that were assigned an ineffective mentor and the other two participants that were not assigned a mentor nor had any peer support described their transition as stressful. Although the four individuals persevered, peer support could have made this transition less stressful.

Theme 2: Administration Support. The four participants that had a positive transition also experienced support from their department's administration. These administrators helped guide these individuals by discussing their expectations for teaching, scholarship, and research. They also stated that these administrators held regular meetings to ensure they were meeting those expectations and were directly involved in introducing them to peers and assigning mentors that would assist in their success. One participant noted that there is also support from the administration about going to a "team-based learning conferences as this is supporting best practice in the field of teaching." The administration fully supports and helps encourage new faculty to be 
prepared. The four individuals that did not have a positive mentor relationship nor one at all described a lack of or an unawareness of what is needed as support from their administration. These four participants that did not have proactive administration support described their transition as difficult. When these individuals sought information from their administrators, they gave little guidance; however, they were not sure what they needed to know and only asked questions when they were already stuck or stressed about a situation. One participant stated, "there was no guidance when teaching began, and I was assigned to teach four classes as a novice faculty member. There was no guidance on the act of teaching nor how to create subject content and deliver it successfully." This participant had to learn the timing of a lecture and how to use learning activities to ensure student benefited. This stressful period led to a lot of crying in the beginning but overall persistence. Although the four individuals persevered, administration support could have made this transition less difficult.

Theme 3: Institutional Support. All participants stated that the faculty orientation provided some guidelines about expectations for teaching, research, and scholarship based on promotion standards; however, since all the faculty in this study are clinical track, they felt that this orientation was directed more toward tenure-track faculty. The only downfall to this orientation is that it is only offered once a year, in August. One participant was hired in February and had been working for six months before going to this orientation. This participant felt that she did not need the orientation because she had already navigated the institution by that time on her own. One institutional service that all 
participants have stated that has been beneficial is the services of the Office of Teaching and Learning (OTL). They have provided basic support for learning management systems and how to design a course within it - the participants that did not have administrative and mentor support sought out institutional support, more so than the participants that had active support. Although all participants have attended a workshop from the OTL, the participants without administrative or mentor support attended many OTL workshops and information sessions. Although services are sought out by the faculty members and workshops are only offered during a specified period yearly, they felt that the institution is beginning to understand the needs of faculty members and are beginning to provide assistance in ensuring these needs are met.

Theme 4: Interaction With Students. From the observations, all three participants seemed to have a positive relationship with their students. They seemed to care, make their lectures interactive and used probing hints when a wrong answer was given. One participant even praised a student for giving a good example, which encouraged the students to provide more feedback during lecture. This particular participant stated, "There have been some errors, but the students have been very supportive." From the interviews, each participant stated they were nervous about teaching in the classroom. The four participants with a positive transition regularly spoke with their mentor or administrator for advice to ease their nervousness while the other four participants had to learn about how to interact with students positively on their own. One of these four participants told the students that they were new to teaching and that 
they are learning together, so the students understand the position of a professor in a new role. Even though the student to professor relationship seemed positive, one participant, in particular, could not believe that she received low evaluation scores from some students. One comment suggested that she was "arrogant." Upon self-reflection, she deemed that she could have come across that way as a defense mechanism because she was not entirely familiar with the content and did not know how to re-direct the student to find the answer. The other participants did not comment on their evaluation scores for their first class.

\section{Theme 5: Instruction Methodology and Educational Technology Training.}

The pharmacy participants were the only individuals in this study that received any formal instructional methodology and technology training. One participant discussed the outline of the topics covered in this teaching certificate, which included "reading, assignments, a teaching portfolio, a teaching philosophy, discussion facilitation, and creating a lecture." One participant stated that she did not have formal training; however, she had much support from her mentor and administrator about how to create a lecture, syllabus, and rubric. Four participants sought as much assistance from OTL, but they offered limited workshops relating mostly to the learning management system and grading. These four individuals did their research on how to create a lecture, syllabus, and rubric on their own. Although these four individuals did not have as much support as the others above, one participant, found a peer in another program that offered guidance and assistance about teaching, which gave her the emotional support to persevere. 


\section{Validity}

For internal validity, a follow-up meeting was arranged to review the interview transcriptions as a way to perform member checking. Active junior health science participants were used as a source of member checking. They used the transcribed transcripts as an interpretation report conducted by the researcher to verify the authenticity of the information provided by the participants. Since the report combined information from many participants, the role of member checker was established to avoid any distress in the participant. The participant's sole purpose of member checking, in this study, was used as a source of error reduction and to identify missing information. When the participants affirmed that the information was completed the study was then deemed credible. If discrepancies were noted a separate reviewer, that is not involved in the study, was asked to review the responses to avoid researcher bias. This information helped triangulate and achieve a broader perspective of the results of teacher preparedness, support, and enhancing faculty member retention. Triangulation, according to Clark (1967), helps determine if there is any bias, to coordinate what the instructors stated in the interview as the truth and if the teachers were prepared in what they were trying to accomplish. For this study, the purpose of triangulation was to converge the information given by each participant during the interview and observational process on their perceptions on the first years of teaching. 


\section{Limitations}

In this study, not all perceptions about the support needed for junior faculty were attained as only a relatively small portion of health science practitioners exist within WSU. Since this study researched current junior faculty the needs of future junior faculty support may change. Changes made to support programs or mentorship will need to be adjusted as the perceptions of support shifts. Possible further studies need to be conducted in order to gain a more in depth knowledge of the support needed for future faculty members.

Observations were only completed on three out of the eight participants. Since the data collection was arranged over a six-week period, the larger health science program participants do not teach classes during the spring and summer semester; therefore, being unable to view their classroom practice. Even if the data collection period were opened to five months, this would only capture two more participants as the pharmacy participants only teach during the winter semester. Possible future studies should be conducted to gain a more in depth knowledge about preparedness in the classroom setting.

Two of the eight participants have yet to teach full time in their own classroom. Their experiences and answers to the interview questions were based from teaching in the residency teaching certificate program or from a part time teaching experience they had at WSU in the same program. 


\begin{abstract}
Summary
The problem that framed this study was to gather perceptions of health science faculty members on their preparedness and support in their first five years of teaching. The purpose of this study was to examine these perceptions which explored strategies that fostered support for transitioned health science faculty members. The data provided insight into a central research question: How do junior health science faculty members describe their preparation in teaching and how does their experiences intersect in the classroom? The data informed and offered recommendations to help novice health science faculty members enhance their preparedness through institutional support and mentorship programs.

Section 2 included the study's research design and methodology. It also described the participants, the data collection, and analysis processes. Section 3 will define the project goals, recommendations for supporting faculty members and discuss implications for social change.
\end{abstract}




\section{Section 3: The Project}

\section{Introduction}

Included in this section are the project's goals and rationale, learning outcomes, and target audience along with a review of the literature that I used to guide the development of the project. The section concludes with a recommendation for project evaluation and a discussion of the implications of the project. I intend to present my findings on the preparedness of junior faculty members for their teaching assignments to the administrators of the College of Pharmacy and Health Sciences (EACPHS) at WSU. This presentation is expected to help administrators devise strategies that will prepare and support junior faculty members from their clinical appointments to academia.

In the data that I obtained from the interviews and observations, the primary concern seemed to be the lack of proactive support (peer, administrative, or institutional) that would help participants be prepared. Therefore, I devised the presentation to address administrators' handling of the transition to academia for junior faculty members. Administrators have a responsibility to guide a new faculty member and help initiate their success. Once administrators provide support through the initial orientation phase, it can then be the responsibility of the new faculty member to rise to the challenges in academia.

The second most common perception was that junior faculty members were nervous about handling a classroom setting. This included how to present material, handle student behaviors, and express confidence. Although all of the participants are 
experts in their field, many felt that they did not know what to expect from students. One participant stated, "I felt least prepared in feeling that the students may go beyond my scope of knowledge and ask questions that I could not answer yet." There are many added pressures on new faculty members; the classroom setting is one where multifaceted items such as content delivery, redirection, and timing are things that should be discussed to prepare individuals better. The need for mentorship and guidance from seasoned faculty members is necessary to ease the transition to a classroom setting. A mentor can also discuss expectations of a classroom environment; it can then be the responsibility for the new faculty member to rise to their challenges in a classroom setting.

The goals of this project were to obtain an in-depth understanding of the participants' perceptions of preparedness to teach through interviews and observations. From these perceptions, ideas can be merged into a cohesive unit that assists administrators as well as new faculty members in areas where support is needed. Administrators have a responsibility to help initiate a successful transition to academia for new faculty members (Davis \& Waite, 2014). I created this project in order to help administrators of EACPHS at WSU understand the needs and concerns of junior faculty members to better prepare and support them in their first years of teaching. Once these needs are addressed, it can then be the responsibility for the new faculty member to rise to their challenges to become successful in academia. A long-term goal of this project is for it to be used to help all junior faculty members, not only health science-related faculty members, at the university. 


\section{Rationale}

The presentation for the EACPHS administrators was designed to help them devise strategies that will better support and prepare junior faculty members during their first years of teaching. Specifically, I developed the presentation based on the top five areas that were identified as themes from analysis of study data: peer mentoring, administration support, institutional support, interaction with students, instructional methodology, educational technology training, and professional development. These themes brought to light the issues that junior faculty members faced during their transition. Once administrators know where junior faculty members need support, they can provide more proactive guidance by creating positive peer mentor relationships and induction programs that will be available to a new faculty member when beginning their role at WSU. Future faculty members will be able to see for themselves how an induction program and positive peer mentor relationships foster positive learning experiences that build confidence.

\section{Review of the Literature}

I conducted an extensive search of the literature using the following key terms: new faculty members, administrative support for new faculty, and first-year faculty concerns. I obtained the information by performing a search of electronic databases available through Walden University, such as ERIC and Education Source. The results are presented according to the most common themes discovered in the literature. 


\section{Challenges for Those Beginning to Teach}

The transition from practitioner to a faculty member is not an easy task as the environments and culture differ dramatically. This transition is difficult due to an already achieved level of expertise clinically, which they now return to the role of novice. These

new faculty members have worked in a clinical setting and developed the skills necessary to be successful in that environment; however, they must start all over when they reach academia as the focus changes from patient to student with different needs. The ability to maintain the connection, practicality, and identity to the clinical field is a struggle once the move to academia is made (Kniess et al., 2017).

Health science educators have the drive to advance clinical practice by extending their role through laboratory simulations and teaching in the classroom (Burns et al., 2013). Moving from clinical practice to academia is a difficult transition. These academics require socialization into the ways and processes of the insitution as well as how to map their new career (Reddy, Searle, Shawa, \& Teferra, 2016). Some new faculty members lack professional confidence and may function in a type of survival mode to make the transition seem less stressful. The focus tends to lie on their own needs, in particular, classroom management, curriculum, and instructional content (Shaleh et al., 2015). Handling this part of their new career on their own can cause added stress, which may lead to poor student outcomes. There have been studies that have shown the challenges faced by new faculty members, which contribute to a high rate of stress and a lack of preparedness (Pothero, 2015). Being able to provide an induction program for 
new faculty that includementorship, professional development, departmental and institutional support help provide the support structure required for the new hires (CCSESA, 2016). Not only does this assist in a new facutly member's support to begin to teach but this allows for a positive impact on student outcomes.

\section{Efficacy of Induction Programs}

The participation and creation of induction programs has yielded positive results for many institutions in terms of new faculty member and student outcomes (CCSESA, 2016). Whether a formal or informal induction program exists a new faculty member feels less stress during their transition to academia. A study by Ingersoll and Strong (2011) showed that institutions with induction programs have an increased likelihood that an instructor will remain in the field of academia. Induction also increases the likelihood that the individual will remain at the institution because of the added support systems (Davis \& Waite, 2014). The Ingersoll and Strong (2011) study also shows that if individuals are involved in some support system, they are more effective in various aspects of teaching and developing better time management skills earlier; in addition, they can adjust classroom activities to meet the students' needs better. These positive outcomes, in turn, create better student outcomes as demonstrated through higher results on academic achievement tests.

\section{University Support}

It is ultimately the responsibility of the university to prepare new faculty members to meet the expectations for their current role by helping them acclimate to their new 
environment successfully. Also, certain knowledge is needed to perform adequately within the institution, which includes understanding the culture, expectations, and values of the university. In a faculty member's new career, institutions of higher learning should assist in preparing the individual for academic life. Junior faculty members need support from their institution, administrators and department faculty. It is the institution's responsibility to lessen faculty member stress by having a better understanding of the support they need for their development (Saka, Shoutherland, \& Kittleson, 2013). Induction to an institution means that improvements can be made to teaching practices and education of junior faculty members (Davis \& Waite, 2014). As the demands on higher educational institutions increase the need to support and develop staff in quality, accountability, and performance issues must be addressed (Reddy et al., 2016). With proper planning, a formal or informal induction to the university can achieve the objectives necessary for a junior faculty member's success. The university can initially support the idea of induction through communication. Communicating prior to instituting a program is critical to its success and fosters a positive environment (Holmberg-Wright, 2013). The institution could raise awareness about the importance of induction through mentorship; provide recognition and resources to help support a junior faculty members transition to academia. This awareness can be distributed at orientation and also offer some pamphlet to ensure the message was delivered about institutional support. 


\section{Support by Administrators}

Good administrators understand the importance of supporting and preparing their junior faculty members to meet the expectations of their current role and help them fully acclimate to their new environment successfully. It is the academic administrator's role to ensure the junior faculty members fully understands the review process, expectations for teaching, promotion, service, and research. Administrators can do this by coordinating the support system needed for junior faculty members through mentorship or induction. Coordination should be clearly communicated for items such as program objectives, expectations of mentors, and expectations of junior faculty members (Holmberg-Wright, 2013).

It is imperative to mention that positive interpersonal relationships in successful educators have played a significant role in binding individuals to their occupations (Howes \& Goodman-Delahunty, 2015). By understanding the needs of junior faculty members challenges can be diminished which increases the preparedness for newly transitioned faculty members (Barak \& Levenberg, 2016). Although the administration has a role in assigning mentors to new faculty, they should consider the following prior to the assignment of a mentor: mentors should be respectable, have a good teaching record and personally competent individuals (Holmberg-Wright, 2013).

\section{Support by Peer Mentors}

The term mentorship is used collaboratively to strengthen the experience of individuals in the workplace. Therefore, the need for mentorship should be tailored to the 
needs of faculty members and enhancing their transition to academia. Calderwood and Klaf (2014) discussed the importance of supporting faculty members to build a strong foundation for their success in the professoriate in items such as learning theory, student learning, and service. The need for mentorship provides opportunities for growth of junior faculty members. Faculty learning communities and mentorship programs are rooted in the works of John Dewey who supported the idea of shared, practical learning (Medina, Tomsek, \& Bowers-Pippin, 2015). These programs would provide opportunities like active engagement, collaboration, and self-directed exploration with senior faculty members about teaching and learning (Medina et al., 2015).

Considering the needs of a junior faculty member, the distinction between formally assigned to informally assigned mentors make a difference. The goals of a formal mentor are usually defined by the institution's objectives, whereas, an informal mentor evolve align with the individual's career needs (Thomas, Bystydzienski, \& Desai, 2015). The ultimate goal of a mentor is the ability to assist in understanding the environment, achieve professional potential, and assist with teaching resources. By having an open and positive relationship with the administration, the need for mentorship can be successfully addressed and implemented. It is fundamentally important to note that positive mentor relationships exist when they are mutually exclusive (Bressman, Winter, \& Efron, 2018). Change happens when there is a mutual trust between mentor and mentee. In addition, it is worthy to note that mentoring that builds on this trust by providing a type of formative assessment can allow the new faculty member to think 
deeply about their teaching with a way of continuous improvement (Efron, Winter \& Bressman, 2013). By providing feedback between mentor and mentee, they can make decisions together without any judgment being applied to an already stressful new career path.

\section{Professional Development}

The term professional development is used collaboratively to enhance the experience of individuals in the workplace. Faculty development is defined as the enhancement of faculty members based on the vision and goals of the institution (Bigbee et al., 2016). With that being said, this gives administrators an opportunity to progress based on personal reflection to be able to enhance a new faculty member's transition to academia. This approach has unique benefits to inclusiveness and cohesiveness within the department and college that considers the social and educational aspects of the new faculty member.

In addressing the purpose for professional development programs, Slimmer (2012) discussed objectives relative to health science faculty members improvement that encourage the enhancement of teaching practices, helps facilitate the transition from clinician practitioner to a professor, and supports the implementation of evidence-based teaching practices. Calderwood and Klaf (2014) discussed the importance of supporting faculty members to build a strong foundation for their success in the professoriate. The authors related the importance of service, student learning, and learning theory. The need for faculty development provided opportunities for growth of junior faculty members as 
well as administrators. Shared practical learning programs are developed from faculty learning communities and are rooted in the works of John Dewey (Medina, Tomsek, \& Bowers-Pippin, 2015). The opportunities that this program provides include active collaboration, engagement, and self-directed exploration with senior faculty members about teaching and learning (Medina et al., 2015).

Many influential factors define the role of the professor or instructor in higher education. It can be defined by social and cultural events that influence the differences that occur in the conceptions of the roles of instructors within different societies (Danijela, 2018). The factors that influence their role are internal and external. Internal factors include those that influence an educator's perception of their role. External factors include the expectations and views of their role, which arise within others such as administrators and students. Both factor types play an essential part of a teacher's professional identity. Educator's in higher education develop within the institution when they begin to create their professional identity. This happens through defining and recognizing the various roles instructors will take on in a classroom setting, through mentorship or professional development courses (Gjedia \& Gardinier, 2018). Once the practitioner transitions to academia they become a whole person in the classroom setting and an expert in their field of study. When we take into account the ability to teach with content knowledge only then can success be linked for instructor to student. Through professional development, one can manage the profession by helping prepare these 
individuals through expectations about educational methodologies that can enhance their already acquired content expertise.

\section{Project Description}

Junior faculty members require support to transition successfully to academia. Support is demonstrated with mentorship on career development and scholarly productivity (Fountain \& Newcomer, 2016). The presentation developed is based upon the results identified from this study that will assist administrators in communicating strategies that will help support junior faculty members in their first years of teaching. My duties will include preparing the materials needed such as handouts to all participating program directors.

\section{Implementation}

I developed the presentation (see Appendix D) according to the main areas of concern noted from the research: peer mentoring, administration support, institutional support, interaction with students, instructional methodology and educational technology training. I foresee the implementation to take two days and I will serve as the primary facilitator for the project. The deans and program directors will meet for a total of two days to view the presentation, discuss overall goals, and make necessary revisions. Once the administrators have viewed the presentation, they will be given a tool to provide feedback for additional changes needed for a successful program induction process. After the presentation and necessary revisions the program directors or designates can utilize 
the induction package when new faculty members arise in their health science departments.

\section{Resources}

Few resources are needed to complete and implement this project. Once the study is complete, I will have my presentation reviewed by the Deans of health sciences and program directors at WSU. After they have completed their review, I will make any necessary revisions. I will print copies of the presentation and induction package and give them of this study for their feedback. After they have completed their review, I will make any necessary revisions.

A large room where the presentation will be given is required. The PowerPoint will be electronically stored and will be shown on a projector. Since the EACPHS hold regular meetings it will not be difficult to access administrative staff. The only cost to me will involve printing the presentation for participant review.

\section{Timetable}

Day 1 will include a review of the importance of a support system for new faculty identified in my project study literature reviews and information on preparing new faculty members from the information obtained during interview and observation data collection. The deans and program directors will have the opportunity to share thoughts and ideas during the morning and afternoon sessions. At the start of Day 1 of the presentation, administrators from various health science related fields will share their various 
backgrounds and experience. The introduction period also will include an overview of the goals of this program as well as examples of the program's activities.

Day 2 will focus on examples needed to fulfill a successful induction phase for a new faculty member identified in the research project. Based on feedback from the participants, this session will include information on verbal communication and ensuring administrators know what areas to focus on such as professional development and mentorship. Participants will be given information on appropriate topics to cover using verbal communication of support in order to prepare new faculty for a successful transition. After this final presentation, I will ask for written feedback from the people in attendance of this meeting. Based upon their feedback, I will make the required changes needed to ensure it is relevant to junior health science educators.

\section{Role of the Researcher}

My role during this project was to conduct, analyze, and develop a presentation based on the findings of this study. Now that the presentation is finalized, my responsibility will be to present this information during a meeting with administrative staff at WSU and present ideas about how they can support their new faculty members as well as receive feedback from them about how they can improve this project by catering it to their respective departments. Any ideas or input given will be researched and justified prior to making any changes to this process. 


\section{Role of Administration}

It will be the responsibility of the administration, Deans, department chair, and program directors to review the presentation and induction package. It will also be their responsibility to arrange for me to deliver this content to their representative faculty members. They will decide whether this information offers valid research to help prepare and support junior faculty members.

\section{Role of Professors}

Once the administration receives the presentation, they will decide to arrange for me to deliver this content to their respective faculty members. From there, it will be up to the professor to implement some or all of the strategies that pertain to their department for support. It will be their responsibility to become involved in collaborating with potential mentors to facilitate new ideas on this process. Faculty members that collaborate with others in their professional network tend to produce results that are more meaningful. This networking may generate new ideas that can potentially be added to the presentation.

\section{Project Evaluation Plan}

According to Lodico (2010), evaluation determines a program or project's worth as well as make recommendations for refinement and success. To ensure this presentation is effective, I have related the literature to my study findings to complete my projected goals. My goals, for this project, were to provide strategies that describe where support is needed for new faculty members and offer opportunities that directly relates to the 
perceptions of junior faculty members for administrators. Once this is presented to the administrative staff, I will employ a summative evaluation tool to determine if the ideas that were presented meet the goals of the project. This evaluation tool, feedback questionnaire, will give administrators a chance to review the ideas presented and offer discipline-specific feedback. Providing administrators with this feedback questionnaire will help determine if the goals above have been met.

\section{Project Implications}

Understanding the perceptions of the transition to academia is of vital importance in order to remedy this issue and create positive social change. Health science educators are essential in creating practitioners that support the medical field. The implications for social change not only affects the faculty member and the university but also positively affects the health professions as a community by preventing a shortage. The goal, from this research was to capture these perceptions, present the needs to administration to be fully supported and prepared during their first years of teaching.

This project is important because it may change the way this institution handles new faculty member transitions, resulting in better prepared and supported faculty. With the assistance of mentorship and administrative support, a newly transitioned faculty member can feel prepared which is essential to one's teaching practices. Once this is established the support needed to enhance their practices, and ultimately the student experience will encourage faculty members to thrive at the academic institution. 


\section{Conclusion}

Junior health science faculty members require support from many sources. By creating a program that helps support a new faculty member it lessens the stress felt during their transition to academia. These programs include support by the institution, administrators and other faculty members as mentors. If institutions realize the needs that are required for these individuals to become fully prepared to teach the more guidance they can provide. When these individuals are first hired, administrators must offer support to ensure they are comfortable navigating their new career as well as discuss their expectations in their new role. The program provides vital information to the administration about addressing the needs of new faculty members outlined in a two-day presentation. Through continuous support, the quality of new educators will grow and improve, which in turn will produce effective healthcare practitioners. This program can be the impetus for the expansion to other programs here at WSU. 


\section{Section 4: Reflections and Conclusions}

\section{Introduction}

Section 4 provides a reflection on the research study. In the first half of this section, I outline the strengths and limitations of the project study. I also explain how I have grown as a researcher to become a more scholarly writer. In Section 4, I also consider the importance of social change for universities and communities. Concluding this section, I explain how I plan to conduct future research to promote the support and preparedness of junior faculty members for all colleges of the university.

\section{Project Strengths}

The strength of this study lies in the importance of its topic, which is teaching. Although students' and instructors' needs are constantly changing, educational leaders need to ensure that they meet those needs by helping to prepare instructors, which in turn helps students. Academia is a profession builds on community as they help prepare students to become leaders in the healthcare field. Administrators need to stay engaged and aware of the needs of the faculty members so that these faculty members are able to contribute to the development of strong, influencing members of society.

Being aware of the current perceptions that junior faculty members have to be prepared will continue to be a focus placed on universities if they intend on having effective faculty. This project can easily be implemented into any academic program, not only health science-related fields. The openness of the discussion format can facilitate positive relationships among professionals within their area of expertise and provide 
feedback for continuing research. This study can be implemented with limited resources and relatively few funds. To encompass future research findings, the information in the presentation may need updating.

\section{Project Limitations}

This project's implementation requires a positive outlook on experience and a willingness to participate in the induction process. Junior faculty may not want to participate in the process if their assigned mentor does not have the same philosophies on teaching as they do. Administrators may not want to take time out of their schedules to create this induction process for the junior faculty member. It is possible that some administrators might assign a mentor for the sake of the process. Another possibility is the project could fall apart before it begins. As a result, a junior faculty member could give up on the process and attempt to prepare himself or herself for teaching.

For the research component of this project, I included only participants in the health science-related fields within their first 5 years of teaching at WSU. University professors and administrators often change over the years. Perceptions may be different in a different year from the impressions that I described in this study. The project has not been fully implemented, or field tested, so it remains unknown whether the results of this study will lead to changes made by university administers at WSU.

\section{Recommendations for Alternative Approaches}

I will make every effort to ensure that a positive outlook ensues on the part of the institution, administration, and other faculty members as mentors. Communicating prior 
to instituting a program is critical to its success (Slimmer, 2012). The university can initially support the idea of induction by communicating its importance to its administrators. Then administrators can communicate to their seasoned, faculty members the importance of mentor relationships. Research on appropriately assigned mentors for positive learning are given to administrators to ensure that the participants are properly supported before the process begins. In the continuing intellect of academics, alternative approaches to knowledge transfer through multiple means can occur (Saravathie, Searle, Lester, \& Damtew, 2016). This includes insights into institutional cultural and procedures from seasoned established university faculty. The benefits of this expose the junior faculty to the culture of the university, which would encompass institutional culture as well as mentorship to complete the induction into academia. Although there may not be a way to address the perceptions of future junior faculty members, from this study, there is evidence that a change is currently needed. New faculty communities would be another alternative approach to support networking. These communities can be the driving force for the change that is required. I will let induction participants know that I am available as a liaison to ensure that the process runs smoothly to ease into the transition and implementation of the required program.

\section{Scholarship, Project Development, and Leadership and Change}

\section{Scholarship}

During this process, I have gained greater in-depth understanding of the scholarly approach to research. I gained greater knowledge of the writing process and project 
development. I developed this project in the hope that it would provide new faculty members with the support they need to transition to academia as clinical practitioners. The goal of this study was to develop positive relationships among their peers, students, and administrators to assist in their preparedness to teach.

From the responses gained from the interviews, I gained understanding of participants' frustration about the lack of proactive support when they began their careers in academia. I observed their classrooms and could appreciate the kindness and willingness to learn that they wanted from their students. My hope is to ensure that future junior faculty members will be less stressed and more supported by the people around them in their first years of teaching.

The experience I gained will help me continue in my academic endeavors concerning teaching, service, and scholarship. I have more confidence than I did when I began this journey. I can listen to people, understand their needs, and be able to help them. I feel that this is a tremendous resource as an educator.

\section{Leadership and Change}

Through the process of conducting research, I have developed leadership qualities such as the ability to adapt to change, honesty, compassion, and inspiration. I have listened to many participants about their experiences of what worked and what did not work in regard to teaching, and I have used that information to guide my project in a way that will make a difference, I believe. Leadership is a quality that many people possess. The ability to provide positive outlooks and be able to work with others is a skill. Leaders 
offer guidance and direction for others to follow. Upon presenting this topic to my dean, I noticed that she was immediately intrigued about my findings and that she wanted me to report to her once I had defended my final study so that we can work on a departmental plan. Although not everyone is receptive to change, leaders are the frontline individuals who are the change makers. Since many of the people working at a university have been there for a long time, they may have forgotten how difficult it was during their transition. Bringing awareness of this subject to them can give them a different perspective about welcoming a new group of faculty to build a successful future. The ability to adapt to environments is the way leaders improve society. Technology and healthcare have changed dramatically in recent years. I believe that the ability to do the same as individuals makes both students and faculty members stronger.

\section{Reflection on the Importance of the Work}

This project is important in many ways. I hope to present this material to university administrators to support and help prepare junior faculty members in their ability to teach. I also expect this study would provide thoughts and ideas for continued research developed from this project. This study allowed for collaboration between multiple health science-related fields such as pharmacy, pathologist assistants, physician assistants, and occupational therapists. This collaboration could spark new crossdiscipline research in either scholarship or teaching. Since teaching is the focus for all of our disciplines and we all support the medical field, we can create student professional developmental or service opportunities that help build healthcare teams. This project 
should continue to be used in all health science-related fields when new faculty members are hired or when medical advances have dramatically changed to ensure we continue to support the staff.

\section{Implications, Application, and Directions for Future Research}

This study is not only crucial to healthcare science but to the ideas and methods of future faculty members in order to continue in the research that this study provided. Through continuous collaboration among faculty members and administration, new ideas can be brought forth for future presentations. The implications for this study not only affect the faculty member, administration, and the university but also positively impacts the health professions as a community to prevent faculty member departure. The need for highly skilled individuals is needed by universities (Saravathie et al., 2016). By creating better, more confident and supported faculty members, we create more confident students that support healthcare as a whole (Thomas, Bystyndzienski, \& Desai, 2015).

\section{Conclusion}

Transitioning from clinical practitioner to educator in health sciences is a difficult task, as content experts; they are not necessarily trained to teach in a classroom setting. By providing an induction program, these individuals will be better prepared and supported to teach in a classroom. The knowledge they will gain through positive mentor relationships, and administrative support adds value to their transition. The future health care practitioner's lies in the hands of educators like those that are mentioned in this 
study. Well-prepared and supported instructors positively affect all healthcare professionals of the future. 


\section{References}

Baker, V. L., Pifer, M. J., \& Lunsford, L. G. (2016). Faculty challenges across rank in liberal arts colleges: A human resources perspective. Journal of Faculty Development, 30(1), 23-29. Retrieved from https://ezp.waldenulibrary.org/login?url=https://search.ebscohost.com/login.aspx? direct=true $\& \mathrm{db}=$ eric $\& A N=E J 1133608 \&$ site $=$ eds-live $\&$ scope $=$ site

Banks, J.(2012). Development of scholarly trajectories that reflect core values and priorities: A strategy for promoting faculty retention. Journal of Professional Nursing, 28(6), 351-359. doi:10.1016/j.profnurs.2012.04.002

Barak, M. B., \& Levenberg, A. A. (2016). A model of flexible thinking in contemporary education. Thinking Skills \& Creativity, 22, 74-85. doi:10.1016/j.tsc.2016.09.003

Baxter, P., \& Jack, S. (2008). Qualitative case study methodology: Study design and implementation for novice researchers. Qualitative Report, 13(4), 544-559. Retrieved from https://ezp.waldenulibrary.org/login?url=https://search.ebscohost.com/login.aspx? direct=true $\& \mathrm{db}=$ eric $\& \mathrm{AN}=\mathrm{EJ} 824836 \&$ site $=$ eds-live $\&$ scope $=$ site

Bedir, G. G. (2017). Perceptions of teaching efficacy by faculty members. International Journal on New Trends in Education \& Their Implications (IJONTE), 8(1), 51-61. Retrieved from https://ezp.waldenulibrary.org/login?url=https://search.ebscohost.com/login.aspx? direct=true $\& \mathrm{db}=$ eue $\& \mathrm{AN}=120464775 \&$ site $=$ eds-live $\&$ scope $=$ site 
Bigbee, J. J., Rainwater, J., \& Butani, L. (2016). Use of a needs assessment in the development of an interprofessional faculty development program. Nurse Educator, 41(6), 324-327. doi:10.1097/NNE.0000000000000270

Bogdan, C., \& Biklen, S. (2007). Qualitative research for education: An introduction to theories and methods. Boston, MA: Pearson Education.

Bondoc, S. (2006). So you want to teach: Strategies for new adjunct faculty. OT Practice, 13(11), 10-17.

Bressman, S., Winter, J. S., \& Efron, S. E. (2018). Next generation mentoring: Supporting teachers beyond induction. Teaching \& Teacher Education, 73, 162170. doi:10.1016/j.tate.2018.04.003

Briseño-Garzón, A., Han, A., Birol, G., Bates, S., \& Whitehead, L. (2016). Faculty perceptions of challenges and enablers of effective teaching in a large researchintensive university: Preliminary findings. Collected Essays on Learning \& Teaching, 9, 133-143. Retrieved from https://ezp.waldenulibrary.org/login?url=https://search.ebscohost.com/login.aspx? direct=true $\& \mathrm{db}=$ eric $\& \mathrm{AN}=\mathrm{EJ} 1104500 \&$ site $=$ eds-live $\&$ scope $=$ sit

Burns, S., Merchant, C., \& Appelt, E. (2013). Campus survey on the status of the scholarship of teaching and learning (SOTL) by health sciences faculty. Education, 133(4), 502-512. Retrieved from https://ezp.waldenulibrary.org/login?url=https://search.ebscohost.com/login.aspx? direct $=$ true $\& \mathrm{db}=$ edsgea $\& \mathrm{AN}=$ edsgcl.336280971\&site=eds-live $\&$ scope $=$ site 
Calderwood, P. E., \& Klaf, S. (2014). Facilitating mentoring across three models of faculty work: Mentoring within a community of practice for faculty development. Journal on Centers for Teaching \& Learning, 6, 59-91. Retrieved from https://ezp.waldenulibrary.org/login? url=https://search.ebscohost.com/login.aspx?direct=true \&db=eue \&AN=10869248 $1 \&$ site $=$ edslive $\&$ scope $=$ site

Cherubini, L. (2007). Speaking up and speaking freely: Beginning teachers' critical perceptions of their professional induction. Professional Educator, 29(2), 1-12.

Clark, N., Alcala-Van Houten, L., \& Perea-Ryan, M. (2010). Transitioning from clinical practice to academia university expectations on the tenure track. Nurse Educator, 35(3), 105-109.

https://doiorg.ezp.waldenulibrary.org/10.1097/NNE.0b013e3181d95069

Creswell, J. (2012). Qualitative, quantitative, and mixed methods approaches (3rd ed.). Thousand Oaks, CA: Sage.

Danijela, M. (2018). The teacher's role and professional development. International Journal of Cognitive Research in Science, Engineering, and Education, 6(2), 3346.

Davis, B. H., \& Waite, S. F. (2006). The long-term effects of a public school/state university induction program. Professional Educator, 28(2), 1-10.

Dewey, J. (1897). My pedagogical creed. School Journal, 54(1), 77-80.

Dewey, J. (1938). Experience and education. New York, NY: Kappa Delta Pi. 
Dinsmore, D. D., Baggetta, P., Doyle, S., \& Loughlin, S. M. (2014). The role of initial learning, problem features, prior knowledge, and pattern recognition on transfer success. Journal Of Experimental Education, 82(1), 121-141.

doi:10.1080/00220973.2013.835299

Droux, J. J., \& Hofstetter, R. R. (2015). Constructing worlds of education: A historical perspective. Prospects (00331538), 45(1), 5-14. doi:10.1007/s11125-015-9337-2

Dunham-Taylor, J., Moore, C., McDaniel, S., \& Walker, J. (2008). What goes around comes around: Improving faculty retention through more effective mentoring. Journal of Professional Nursing, 24(1), 337-346. https://doiorg.ezp.waldenulibrary.org/10.1016/j.profnurs.2007.10.013

Efron, E., Winter, J., Bressman, S. (2013) Toward a more effective mentoring model:

An innovative program of collaboration. Journal of Jewish Education, 78(4), 331-336. doi-org.ezp.waldenulibrary.org/10.1080/15244113.2012.734431

Fain, E. A. (2011). Bridging the gap. Helping more practitioners become academics. OT Practice, 16(3), 8-12. Retrieved from https://ezp.waldenulibrary.org/login?url=https://search.ebscohost.com/login.aspx? direct $=$ true $\& \mathrm{db}=\mathrm{rzh} \& \mathrm{AN}=104847428 \&$ site $=$ eds-live $\&$ scope $=$ site

Fountain, J., \& Newcomer, K. E. (2016). Developing and sustaining effective faculty mentoring programs. Journal of Public Affairs Education, 22(4), 483-506. Retrieved from 
https://ezp.waldenulibrary.org/login?url=https://search.ebscohost.com/login.aspx? direct $=$ true $\& \mathrm{db}=21 \mathrm{~h} \& \mathrm{AN}=119162955 \&$ site $=$ eds-live $\&$ scope $=$ site

Friedman, H. H., Hampton-Sosa, W., \& Weiser Friedman, L. (2014). Solving the megacrisis in education: Concrete effective solutions. Journal of Educational Technology, 10(4), 6-17. Retrieved from https://ezp.waldenulibrary.org/login?url=https://search.ebscohost.com/login.aspx? direct $=$ true $\& \mathrm{db}=$ eric $\& \mathrm{AN}=\mathrm{EJ} 1098584 \&$ site=eds-live $\&$ scope $=$ sit

Garrison, M. J., \& Rexeisen, R. R. (2014). Faculty ownership of the assurance of learning process: Determinants of faculty engagement and continuing challenges. Journal of Education for Business, 89(2), 84-89. doiorg.ezp.waldenulibrary.org/10.1080/08832323.2012.761171

Gjedia, R., \& Gardinier, M. P. (2018). Mentoring and teachers' professional development in Albania. European Journal of Education, 53(1), 102-117.

Glaister, P., \& Glaister, E. (2013). Standards of university teaching. MSOR Connections, 13(2), 61-65. doi:10.11120/msor.2013.00011

Gourlay, L. (2011). "I'd landed on the moon". A new lecturer leaves the academy. Teaching in Higher Education, 33(1), 591-601. doiorg.ezp.waldenulibrary.org/10.1080/13562517.2011.605548

Guan, S., \& Stanford, D. (2016). Learner and faculty support. New Directions for Higher Education, 2016(173), 65-74. doi:10.1002/he.20180 
He, B., Cooper, J., \& Tangredi, C. (2015). Why do I stay? Teacher Education Quarterly, 42(1), 49-66. Retrieved from https://ezp.waldenulibrary.org/login?url=https://search.ebscohost.com/login.aspx? direct $=$ true $\& \mathrm{db}=$ eric $\& \mathrm{AN}=\mathrm{EJ} 1090615 \&$ site=eds-live $\&$ scope $=$ site

Hentges, J. (2012). Why do beginning teachers leave the profession? What can be done about it? Global Education Journal, 2012(3), 100-105. Retrieved from https://ezp.waldenulibrary.org/login?

url=https://search.ebscohost.com/login.aspx $?$ direct=true $\& d b=e u e \& A N=83529720$ $\&$ site $=$ edslive $\&$ scope $=$ site

Holmberg-Wright, K. (2013). Mentoring Programs For Junior Faculty: A Turning Point In Career Advancement. Insights To A Changing World Journal, 2013(4), 43-53.

Hope, J. (2015). Help faculty members be more effective with training, ongoing support. (cover story). Recruiting \& Retaining Adult Learners, 17(11), 1-6. doi:10.1002/nsr.20092

Howes, L. L., \& Goodman-Delahunty, J. (2015). Teachers' career decisions: Perspectives on choosing teaching careers, and on staying or leaving. Issues In Educational Research, 25(1), 18-35. Retrieved from https://ezp.waldenulibrary.org/login? url=https://search.ebscohost.com/login.aspx?direct=true $\& \mathrm{db}=$ eue $\& A N=10238276$ $5 \&$ site $=$ edslive $\&$ scope $=$ site

Kebaetse, M. B., \& Sims, R. (2016). Using instructional consultation to support faculty in learner-centered teaching. Journal of Faculty Development, 30(3), 31-40. 
Retrieved from

https://ezp.waldenulibrary.org/login?url=https://search.ebscohost.com/login.aspx? direct $=$ true $\& \mathrm{db}=$ eric $\& \mathrm{AN}=\mathrm{EJ} 1133579 \&$ site $=$ eds-live $\&$ scope $=$ sit

Kimmel, K. K., \& Fairchild, J. L. (2017). A full-time dilemma: Examining the experiences of part-time faculty. Journal of Effective Teaching, 17(1), 52-65. Retrieved from https://ezp.waldenulibrary.org/login? url=https://search.ebscohost.com/login.aspx?direct=true \&db=eric\&AN=EJ11399 $22 \&$ site $=$ edslive $\&$ scope $=$ site

Kniess, D., Benjamin, M., \& Boettcher, M. (2017). Negotiating faculty identity in the transition from student affairs practitioner to tenure-track faculty. College Student Affairs Journal, 35(1), 13-24. doi:10.1353/csj.2017.0002

Knowles, M. S. (1973). The adult learner. A neglected species. Houston, TX: Golf Knowles, M. S. (1975). Adult education: new dimensions. Educational Leadership, 3385-88.

Komos, M. (2013). "Thanks for asking": Adjunct faculty members' views of effective teaching. Journal on Excellence in College Teaching, 24(4), 133-164. Retrieved from https://ezp.waldenulibrary.org/login? url=https://search.ebscohost.com/login.aspx?direct=true \&db=eue \&AN=95264027 $\&$ site $=$ edslive $\&$ scope $=$ site

Krajewski, S., \& Schwartz, R. (2014). A community college instructor's reflective journey toward developing pedagogical content knowledge for nature of science 
in a non-majors undergraduate biology course. Journal Of Science Teacher Education, 25(5), 543- 566. doi:10.1007/s10972-014-9390-3

Kumi-Yeboah, A., \& James, W. (2012). Transformational teaching experience of a novice teacher. Adult Learning, 23(4), 170-177. doi:10.1177/1045159512457354

Lakin, A. L. (2016). Effective faculty evaluation at the teaching-centered university. International Journal of Educational Management, 30(6), 976-988. doi:10.1108/IJEM-03-2015-0030

Lincoln, Y., \& Guba, E. (1985). Naturalistic inquiry. Thousand Oaks, CA: Sage

Lodico M., Spaulding, D., \& Voegtle, K. (2010). Methods in educational research. (2nd ed.). San Francisco, CA: Jossey-Bass.

McArthur-Rouse, F. (2008). From expert to novice: An exploration of the experiences of new academic staff to a department of adult nursing studies. Nurse Education Today, 28(4), 401-408. Retrieved from https://ezp.waldenulibrary.org/login?url=https://search.ebscohost.com/login.aspx? direct=true $\& d b=$ edsgea $\& A N=$ edsgcl.190796786\&site=eds-live $\&$ scope $=$ site

Medina, M. M., Tomsek, J. J., \& Bowers-Pippin, J. (2015). The use of mentors and partnerships in preparing a future faculty program at a health sciences center. Currents in Pharmacy Teaching \& Learning, 7(2), 145-150. doi:10.1016/j.cptl.2014.11.008

Merriam, S. (2012). Qualitative research: A guide to design and implementation (4th ed.). San Francisco, CA: Jossey-Bass. 
Millea, M., \& Grimes, P. W. (2002). Grade expectations and student evaluation of teaching. College Student Journal, 36(4), 582-590. Retrieved from https://ezp.waldenulibrary.org/login? url=https://search.ebscohost.com/login.aspx?direct=true \&db=eue \&AN=50779145 $1 \&$ site $=$ edslive $\&$ scope $=$ site

Moles, J. (2014). A fair game or no contest? Contested identities in teacher education. Gender and Education, 26(2), 168-179. doiorg.ezp.waldenulibrary.org/10.1080/09540253.2014.888404

Moltó, O. (2011). Re-visiting teaching experiences of a novice teacher in the university: Educational reflections. International Journal of Learning, 17(11), 193-203. Retrieved from https://ezp.waldenulibrary.org/login?url=https://search.ebscohost.com/login.aspx? direct $=$ true $\& \mathrm{db}=$ eue $\& \mathrm{AN}=64439319 \&$ site $=$ eds-live $\&$ scope $=$ site

Murray, C., Stanley, M., \& Wright, S. (2013). The transition from clinician to academic in nursing to allied health: A qualitative meta-synthesis. Nurse Education Today, 34(1), 389-395. https://doiorg.ezp.waldenulibrary.org/10.1016/j.nedt.2013.06.010

Murray, J., \& Wolf, P. (2016). Faculty experience teaching in an interdisciplinary firstyear seminar program: The case of the University of Guelph. Canadian Journal for the Scholarship of Teaching \& Learning, 7(1), 1-19. doi:10.5206/cjsotlrcacea.2016.1.4 
National Commission on Teaching and America's Future (2006). Teacher turnover problem. Retrieved from https://nctaf.org/?s=teacher+attrition $\& \mathrm{x}=0 \& \mathrm{y}=0$

National Education Association (2017). Higher education best practices - teaching and learning. Retrieved from http://www.nea.org/home/33508.htm

Nielsen, C., \& Cappelen, K. (2014). Exploring the mechanisms of knowledge transfer in university-industry collaborations: A study of companies, students, and researchers. Higher Education Quarterly, 68(4), 375-393. doi:10.1111/hequ.12035

Nokes-Malach, T., \& Mestre, J. (2013). Toward a model of transfer as sense-making. Educational Psychologist, 43(3), 184-207. https://doiorg.ezp.waldenulibrary.org/10.1080/00461520.2013.807556

O'Meara, K. (2015). Half-Way out: How requiring outside offers to raise salaries influences faculty retention and organizational commitment. Research in Higher Education, 56(3), 279-298. https://doiorg.ezp.waldenulibrary.org/10.1007/s11162-014-9341-z

O'Meara, K., Lounder, A., \& Campbell, C. M. (2014). To heaven or hell: Sensemaking about why faculty leave. Journal of Higher Education, 85(5), 603-632. https://doi-org.ezp.waldenulibrary.org/10.1353/jhe.2014.0027

Organization for Economic Cooperation and Development (2013). Teaching and learning international survey. Retrieved from http://www.oecd.org/ 
Pothero, A. (2015). Continuous Learning Critical to Career Success. Education Week, 34(18), 10-11. Retrieved from https://ezp.waldenulibrary.org/login?url=https://search.ebscohost.com/login.aspx? direct $=$ true $\& d b=$ edsgov $\& A N=$ edsgcl.399738590\&site=eds-live $\&$ scope $=$ site

Rahmawati, Y., \& Taylor, P. C. (2015). Moments of critical realization and appreciation: a transformative chemistry teacher reflects. Reflective Practice, 16(1), 31-42. doi:10.1080/14623943.2014.944142

Ran Hu1, H., \& Smith, J. J. (2011). Cultural perspectives on teaching and learning: A collaborative self-study of two professors' first year teaching experiences. Studying Teacher Education: Journal of Self-Study of Teacher Education Practices, 7(1), 19-33. doi:10.1080/17425964.2011.558347

Reddy, S., Searle, R. L., Shawa, L. B., \& Teferra, D. (2016). A balancing act: facilitating a University Education Induction Programme for (early career) academics. Studies In Higher Education, 41(10), 1820-1834. https://doiorg.ezp.waldenulibrary.org/10.1080/03075079.2016.1221658

Roberts, R. R. (2016). Are some of the things faculty do to maximize their student evaluation of teachers scores unethical? Journal of Academic Ethics, 14(2), 133148. doi:10.1007/s10805-015-9247-1

Robinson, T. E., \& Hope, W. C. (2013). Teaching in higher education: Is there a need for training in pedagogy in graduate degree programs? Research In Higher Education Journal, 21. Retrieved from 
https://ezp.waldenulibrary.org/login?url=https://search.ebscohost.com/login.aspx? direct $=$ true $\& \mathrm{db}=$ eric $\& \mathrm{AN}=\mathrm{EJ} 1064657 \&$ site $=$ eds-live $\&$ scope $=$ site

Ryan, J. F., Healy, R., \& Sullivan, J. (2012). Oh, won't you stay? Predictors of faculty intent to leave a public research university. Higher Education: The International Journal of Higher Education and Educational Planning, 63(4), 421-437. Retrieved from https://ezp.waldenulibrary.org/login?url=https://search.ebscohost.com/login.aspx? direct $=$ true $\& \mathrm{db}=$ eric $\& \mathrm{AN}=\mathrm{ED} 523633 \&$ site $=$ eds-live $\&$ scope $=$ site

Saka, Y., Southerland, S., \& Kittleson, J. (2013). Understanding the induction of a science teacher: The interaction of identity and context. Journal of Science Education, 43(1), 1221-1244. https://doiorg.ezp.waldenulibrary.org/10.1007/s11165-012-9310-5

Saleh, A. M., Shabila, N. P., Dabbagh, A. A., Al-Tawil, N. G., \& Al-Hadithi, T. S. (2015). A qualitative assessment of faculty perspectives of small group teaching experience in Iraq. BMC Medical Education, 1519. doi:10.1186/s12909-0150304-7

Saravathie, R., Searle, R., Lester, S., \& Damtew, T. (2016). A balancing act: facilitating a university education induction programme for early career academics. Higher Education Training and Development, 41(10), 1820-1834. https://doiorg.ezp.waldenulibrary.org/10.1080/03075079.2016.1221658 
Saunders, G. G., Oradini, F., \& Clements, M. (2017). SMART teaching in new and old classrooms. IAFOR Journal of Education, 5(1), 85-109. Retrieved from https://ezp.waldenulibrary.org/login?

url=https://search.ebscohost.com/login.aspx?direct=true $\& \mathrm{db}=$ eric $\& A N=E J 11417$ $07 \&$ site $=$ edslive $\&$ scope $=$ site

Scott, W., Lemus, D., Knotts, G., \& Oh, J. (2016). Why learner-centered new faculty orientations matter: Organizational culture and faculty retention. Journal of Faculty Development, 30(1), 15-22. Retrieved from https://ezp.waldenulibrary.org/login?url=https://search.ebscohost.com/login.aspx? direct $=$ true $\& \mathrm{db}=$ eric $\& \mathrm{AN}=\mathrm{EJ} 1133613 \&$ site $=$ eds-live $\&$ scope $=$ site

Sethi, A., Ajjawi, R., McAleer, S., \& Schofield, S. (2017). Exploring the tensions of being and becoming a medical educator. BMC Medical Education, 17(1), 62. doi:10.1186/s12909-017-0894-3

Slimmer, L. (2012). A teaching mentorship program to facilitate excellence in teaching and learning. Journal of Professional Nursing: Official Journal of the American Association of Colleges of Nursing, 28(3), 182-185.

doi:10.1016/j.profnurs.2011.11.006

Stake, R. (1995). The art of case study research. Thousand Oaks, CA: Sage

Starman, A. (2013). The case study as a type of qualitative research. Journal of Contemporary Educational Studies / Sodobna Pedagogika, 64(1), 28-43. Retrieved from 
https://ezp.waldenulibrary.org/login?url=https://search.ebscohost.com/login.aspx? direct $=$ true $\& \mathrm{db}=$ eue $\& \mathrm{AN}=86952444 \&$ site $=$ eds-live $\&$ scope $=$ site

Starr, L. L., \& DeMartini, A. (2015). Addressing the needs of doctoral students as academic practitioners: A collaborative inquiry on teaching in higher education. Canadian Journal Of Higher Education, 45(3), 68-83. Retrieved from https://ezp.waldenulibrary.org/login? url=https://search.ebscohost.com/login.aspx?direct=true \&db=eue \&AN=11202992 $8 \&$ site $=$ edslive $\&$ scope $=$ site

Thomas, N., Bystydzienski, J., \& Desai, A. (2015). Changing Institutional Culture through Peer Mentoring of Women STEM Faculty. Innovative Higher Education, 40(2), 143-157. . https://doi-org.ezp.waldenulibrary.org/10.1007/s10755-0149300-9

Turnbull, C., Grimmer-Somers, K., Kumar, S., May, E., Law, D., \& Ashworth, E. (2009). Allied science and complementary health professionals: a new model for Australian allied health. Australian Health Review, 33(1), 27-37. Retrieved from https://ezp.waldenulibrary.org/login?url=https://search.ebscohost.com/login.aspx? direct $=$ true $\& \mathrm{db}=\mathrm{mnh} \& \mathrm{AN}=19203331 \&$ site $=$ eds-live $\&$ scope $=$ site

Valentin, D. (2018). Transitioning from the Lab to Academia: One MLS's Perspective. Critical Values, 11(3), 25-27.

Vygotsky, L. (1978). Interaction between learning and development. In L. Vygotsky (Ed.), Mind in society: The development of higher psychological processes (pp. 
69-94). Cambridge, MA: Harvard University Press.

Wayne State University office for Institutional Research and Analysis (n.d.). Retrieved June 20, 2017 from https://research.wayne.edu/

Weidman, N. (2013). The lived experience of the transition of the clinical nurse expert to the novice nurse educator. Teaching \& Learning in Nursing, 8(3), 102-109. doi:10.1016/j.teln.2013.04.006

Whitfield, T. S., \& Hickerson, C. (2013). The difficult transition? Teaching, research, service: Examining the preparedness of communication faculty entering the academe. Journal of the Scholarship of Teaching \& Learning, 13(1), 1-23. Retrieved from https://ezp.waldenulibrary.org/login? url=https://search.ebscohost.com/login.aspx?direct=true $\& \mathrm{db}=$ eric $\& A N=E J 10116$ $63 \&$ site $=$ edslive $\&$ scope $=$ site

Wilborn, T., Timpe, E., Wu-Pong, S., Manolakis, M., Karboski, J., Clark, D., \& Altiere, R. (2013). Factors influencing faculty perceptions of teaching workload. Currents in Pharmacy Teaching \& Learning, 5(1), 9-13. doi:10.1016/j.cptl.2012.09.011

Yin, R. K. (2003). Case study research: Design and methods (3rd ed.). Thousand Oaks, CA: Sage.

Zydney, J. (2014). Mini anchors: A universal design for learning approach. Techtrends, 58(6), 21-28. https://doi-org.ezp.waldenulibrary.org/10.1007/s11528-014-0799-5 
Appendix A: Access to Participants

MaryAnne Stewart, Assistant Professor Clinical Laboratory Program

[address redacted]

Dear Dr.

\section{Exploring Perceptions about the Transition from Health Care Practitioner to} Academia

I am writing to you as the primary investigator for granting access to participants for the study listed above. I am currently completing my Doctoral degree in Adult Education at Walden University. I am very interested in the needs of health science faculty within their first five years of teaching and want to explore their perceptions in order to positive affect the outcomes of new faculty members at Wayne State University.

The study aims to examine university teachers' perceptions of their preparedness to teach as health science related content experts at Wayne State University during their first years of teaching and recommendations for support needed for the transition from clinical practice to academia.

I have received IRB approval, number 051718B3E, and would appreciate if you could provide me a list of potential participants, under your supervision, that are full-time health science related faculty, in the clinical non-tenure track, within their first five years of teaching. I am also requiring any exit interview documents from any former full-time health science related faculty, in the clinical non-tenure track, within their first five years of teaching. The purpose of using documents as part of the data collection process is to determine as much as possible about the phenomenon of this study to improve outcomes for new faculty members.

Each participant will be given a clear explanation of the study and necessary privacy protection.

If you have any further questions please do not hesitate to call or email me. Once the list of candidates and the exit interview documents are prepared please email them to me, then a letter of consent to the participants will be issued.

Thank you

Yours sincerely, 
Asst. Professor MaryAnne Stewart [e-mail address redacted] [telephone number redacted] 


\section{Appendix B: Interview Questions}

1. Can you tell me your clinical background? How many years have you been in the clinical field prior to pursuing a career in academia? What ranks in the clinical setting have you attained?

2. Why did you decide to transition to academia?

3. Can you describe, and give examples, of your interaction with the students during your first years of teaching?

4. When you began teaching, in what areas did you feel you were the most prepared? (content, classroom management, course design, communicating with students)? Why do you feel that you were so prepared for these things?

5. When you began teaching, in what areas were you the least prepared? (content, classroom management, course design, communicating with students)? Why do you feel that you were least prepared for these things? Provide examples? Support, mentor?

6. In what ways do you feel that your first years of teaching experience could have improved or changed to better prepare you in this transition? Provide examples?

7. Can you describe your experience and knowledge with the content you were given to teach? Can you provide examples?

8. Do you have any training in instructional methodology? Were you confident in teaching the subject matters content? If not, why not? 
9. Have you had any experience with course design or management? Was their support within the institution to help in your transition with course management and design?

10. In what ways has the institution supported you as you began your teaching career? (administration, workshops, orientation). Provide examples?

11. What advice would you give to current novice faculty members that you feel would benefit them when they get hired in academia?

12. Can you add any other information that you feel would be helpful for future clinical practitioners moving to academia so they are prepared and supported in their first five years of teaching? 
Appendix C: Field Note Observational Data

\begin{tabular}{|l|l|}
\hline Observer: & \\
\hline Participant: & \\
\hline Course: & \\
\hline Time: & \\
\hline Duration: & \\
\hline Setting: & \\
\hline Atmosphere: & \\
\hline $\begin{array}{l}\text { Demonstration of } \\
\text { Subject Knowledge: }\end{array}$ & \\
\hline Plan and Deliver a & \\
\hline
\end{tabular}


Appendix D: The Project PowerPoint

\section{Exploring Perceptions about the Transition from Health Science Practitioner to Academia}

Length of Programming: 2 days to coincide with scheduled administrators meeting Location: EACPHS conference room

\section{Induction Examples and Scope}

The scope and intensity of the induction should be geared toward the new faculty's needs. A comprehensive induction generally includes the following components:

- Formal or Informal Orientation: This includes a review of basic university policies and procedures such as where to find instructional resources, forms and templates, a guide to departmental policies such as attendance, grading, and scheduling.

- Mentoring: Assigning a mentor that will fit the needs of the new faculty in terms of goals, research interests, and teaching philosophies. Mentors conduct assessments and observations as well as provide feedback. 
- Professional Development: Incorporates the opportunity for ongoing learning and participation in community networks. This process may help bridge the gap between theory and practice for new faculty members.

\section{Introduction Letter for University Administration and New Faculty Members}

Dear Administration or New Faculty Member,

Various studies have shown that the challenges faced by new health science faculty members in academia causes stress and a lack of preparedness in the classroom. Strategies on how to help with the transition for these individuals include: orientation, mentorship, and professional development. However, the nature and scope of this process should be geared toward the individual needs of the new faculty member. The following will describe strategies for the institution, administration, and the faculty member in order to ease the transition. All necessary examples will be provided to ensure that new faculty member success is achieved through preparedness, which, in turn, will reduce stress.

Sincerely Yours, 
$\underline{\text { Session Day } 1}$

Topic: The Importance of a Support System for New Faculty Members

Time: 2 - 3 hr Morning Session and 2 - 3 hr Afternoon Session

Discussion: What types of support systems have been identified in current literature and recent research

\begin{tabular}{|c|c|c|c|c|}
\hline Topic & Materials & Activities & $\begin{array}{c}\text { Time } \\
\text { Allotment }\end{array}$ & Goals \\
\hline Introductions & & & 15 minutes & $\begin{array}{c}\text { Gain familiarity } \\
\text { of the various } \\
\text { program }\end{array}$ \\
\hline $\begin{array}{l}\text { Background and } \\
\text { Expectations of } \\
\text { New Faculty } \\
\text { Members } \\
\text { through } \\
\text { Orientation } \\
\end{array}$ & $\begin{array}{c}\text { PowerPoint } \\
\text { Handout }\end{array}$ & $\begin{array}{l}\text { Interactive } \\
\text { review of new } \\
\text { faculty } \\
\text { expectations per } \\
\text { program }\end{array}$ & 30 minutes & $\begin{array}{c}\text { Gain an } \\
\text { understanding of } \\
\text { what is needed } \\
\text { for new faculty } \\
\text { members per } \\
\text { program }\end{array}$ \\
\hline Break & & & 10 minutes & \\
\hline $\begin{array}{l}\text { Overview of the } \\
\text { Significance of } \\
\text { support systems } \\
\text { for new faculty } \\
\text { members }\end{array}$ & $\begin{array}{c}\text { PowerPoint } \\
\text { handout }\end{array}$ & $\begin{array}{c}\text { Interactive } \\
\text { review of the } \\
\text { significance of } \\
\text { support systems } \\
\text { for new faculty } \\
\text { program }\end{array}$ & 1.5 hours & $\begin{array}{c}\text { Understand } \\
\text { support systems } \\
\text { identified in } \\
\text { current literature } \\
\text { and recent } \\
\text { research } \\
\end{array}$ \\
\hline Lunch & & & 1 hour & \\
\hline $\begin{array}{l}\text { Discussion about } \\
\text { the Needs of } \\
\text { Mentorship and } \\
\text { Professional } \\
\text { Development }\end{array}$ & $\begin{array}{c}\text { PowerPoint } \\
\text { handout }\end{array}$ & & 2 hours & $\begin{array}{c}\text { Understand } \\
\text { ways to provide } \\
\text { mentorship and } \\
\text { professional } \\
\text { development. } \\
\text { Take learned } \\
\text { materials and } \\
\text { activities back to } \\
\text { new faculty } \\
\text { members }\end{array}$ \\
\hline $\begin{array}{l}\text { Wrap up and } \\
\text { Evaluation }\end{array}$ & Daily Evaluation & & 30 minutes & \\
\hline
\end{tabular}




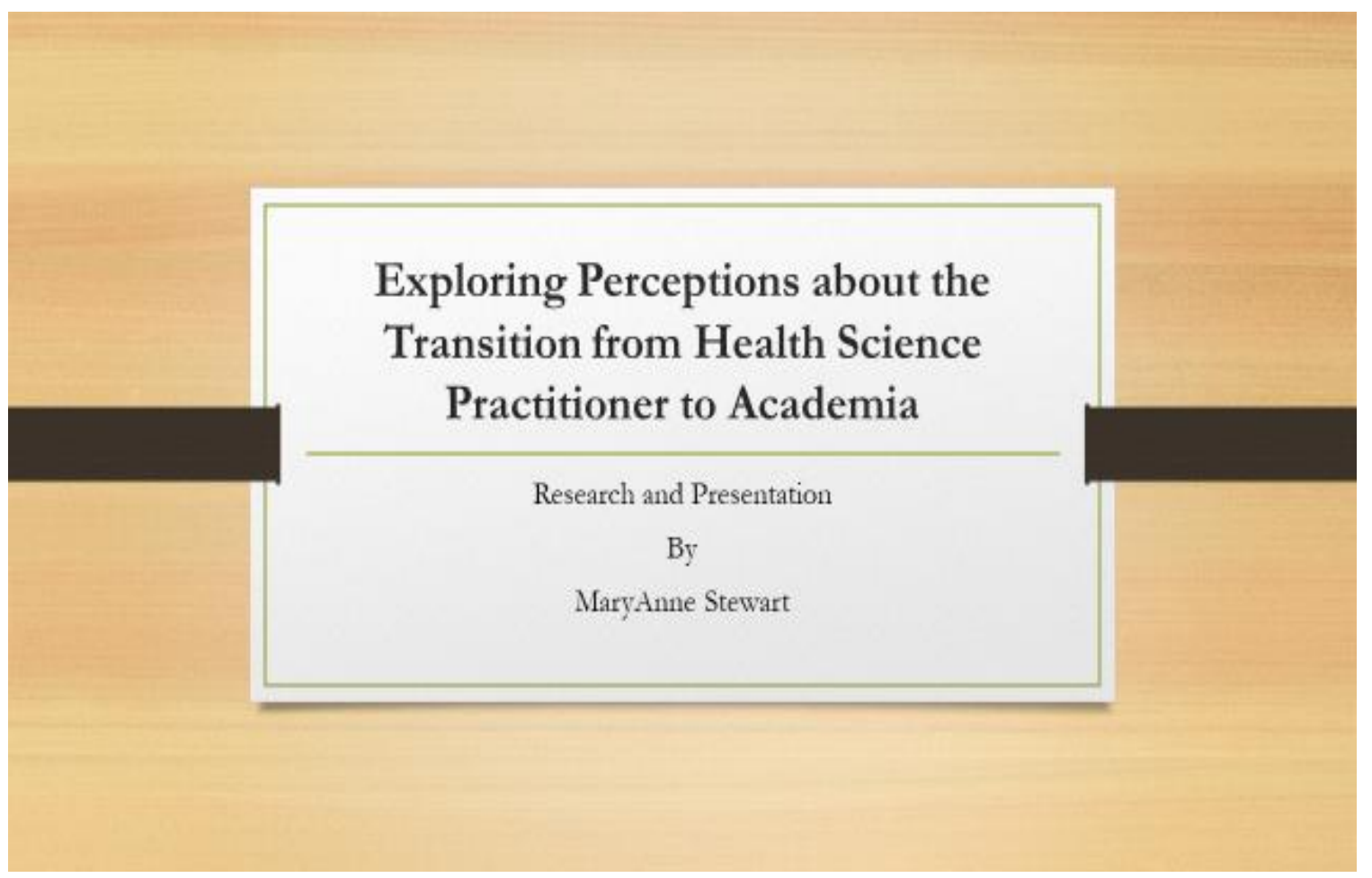




\section{The initial years for teachers are arguably the most difficult period of their development (Fain, 2011)}

\section{Did you Know}

- Qualifications for teaching at a University include a Ph.D. or equivalent in their related field with no mention of training in educational theory and methodology.

- Health science type of instruction requires highly skilled techniques as each program is prepared for national board exams (Saleh, Shabila, Dabbagh, Al-Tawil, \& Al-Hadithi, 2015). 


\section{Expectations}

- Novice faculty members are expected to perform at a level of their advanced peers

- Novice faculty members are expected to transfer knowledge appropriately and handle the added stress of a classroom environment

\section{Significance}

- The goal, from this research is to capture these perceptions and aid instructors in understanding what is required for them to be fully supported and prepared during their transition period.

- Health science educators are necessary to create practitioners that support the medical field 


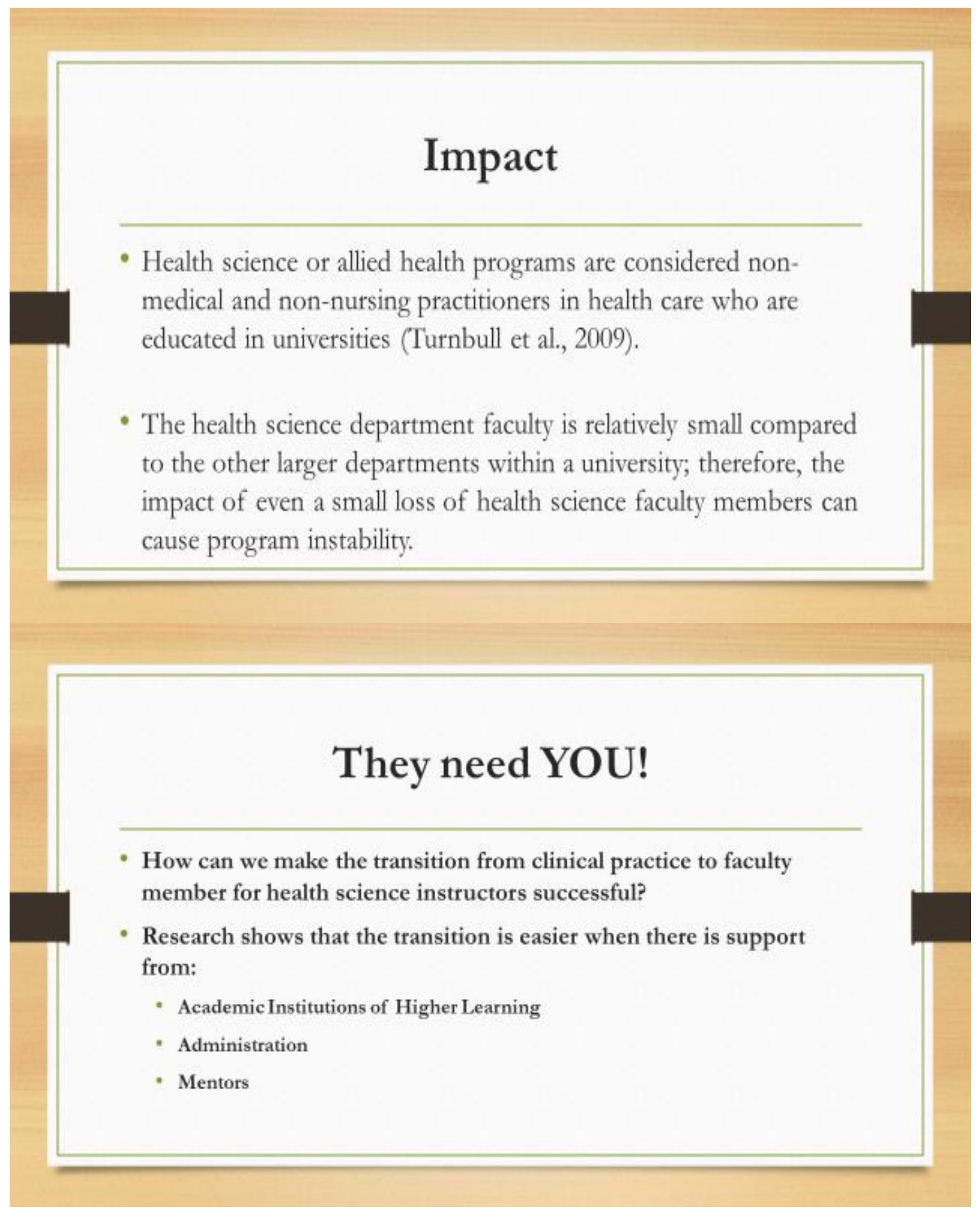




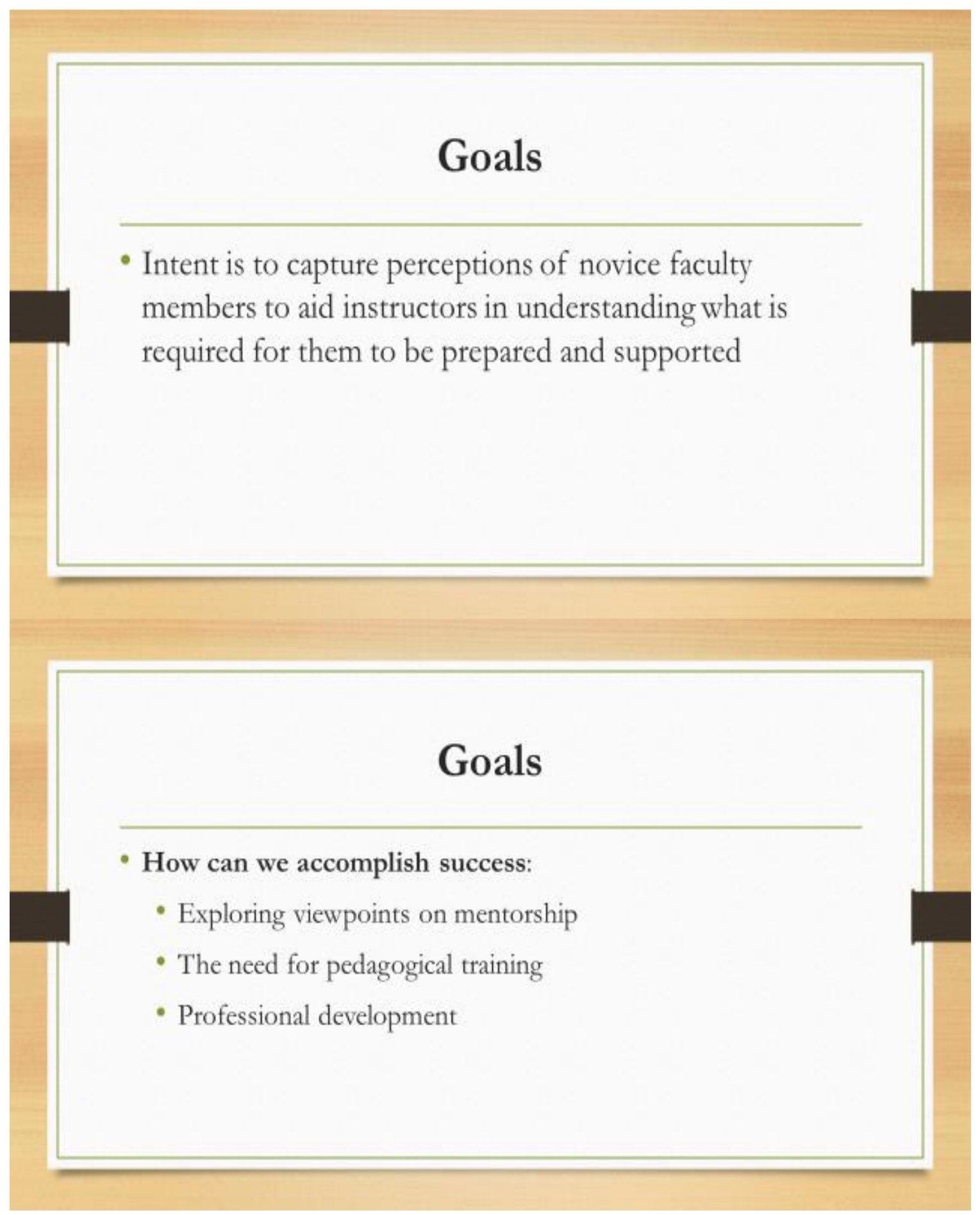



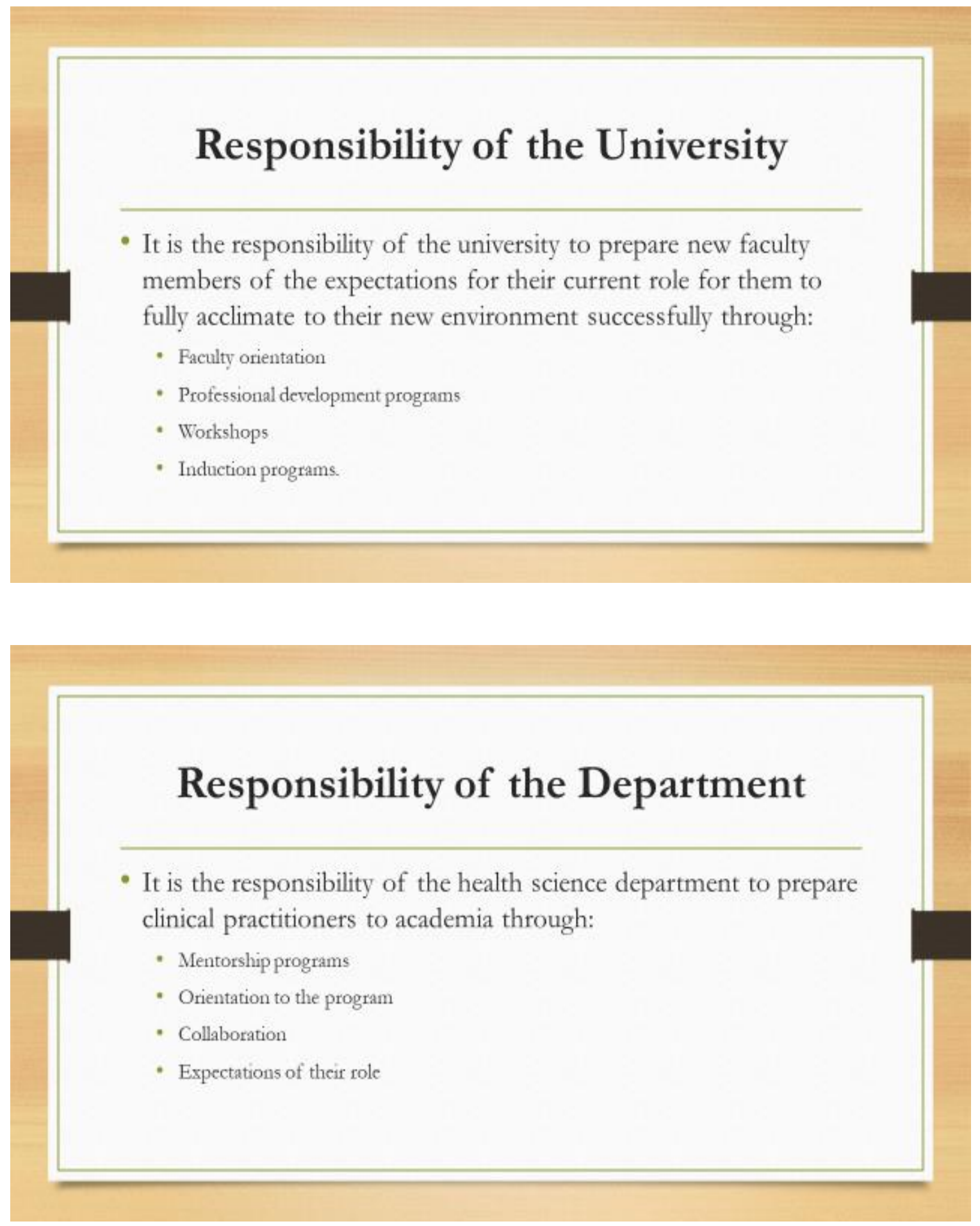


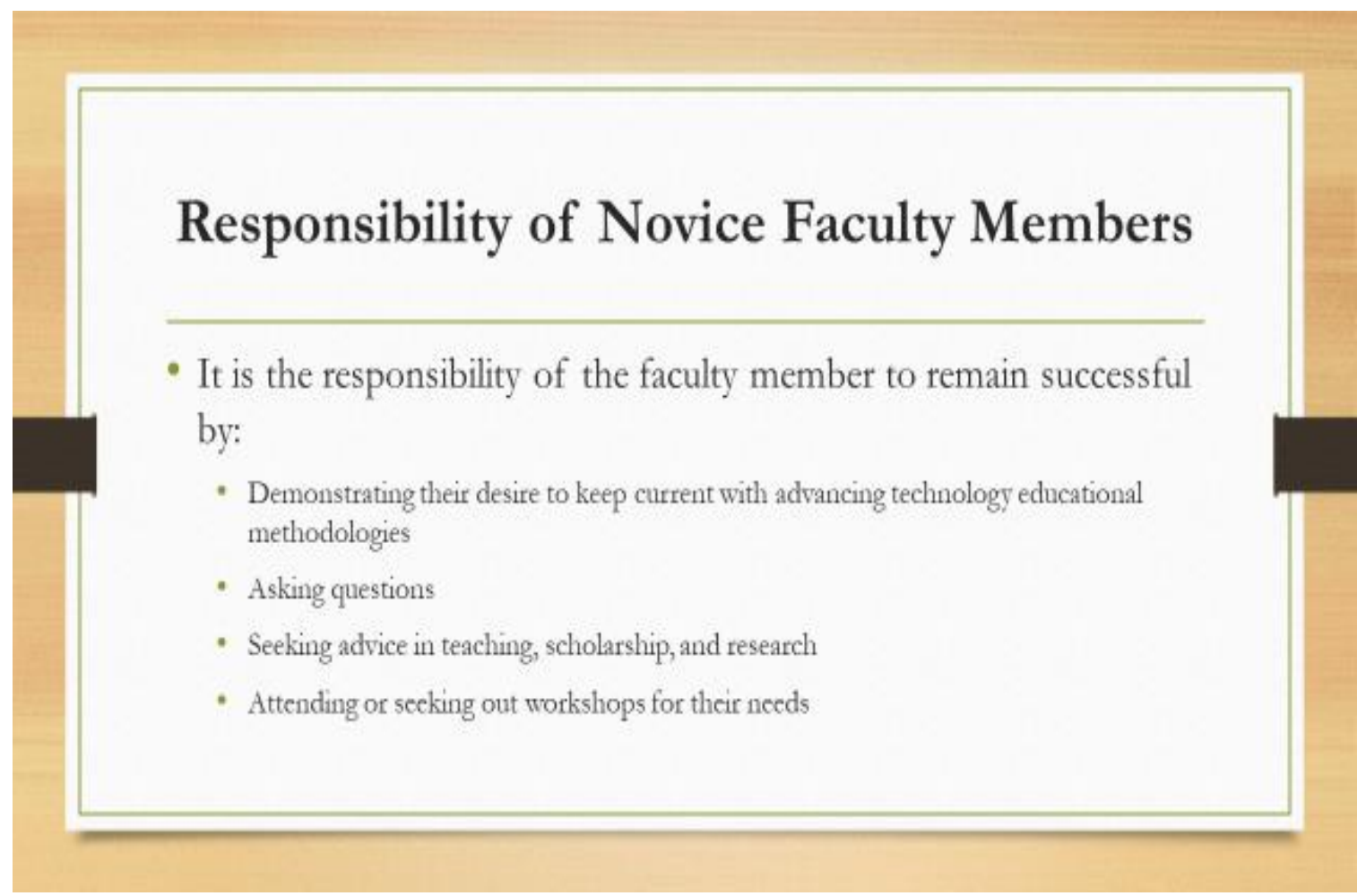




\section{Self-reflection Questions Administration}

- List ways in which you support novice faculty?

- How do you know they are successful?

-What can you do to retain novice faculty members?

\section{Self-reflection Questions Positive Impact}

-What have you learned from your experience as a novice educator?

- Why is it important to you?

- What enhanced your career as an educator? 


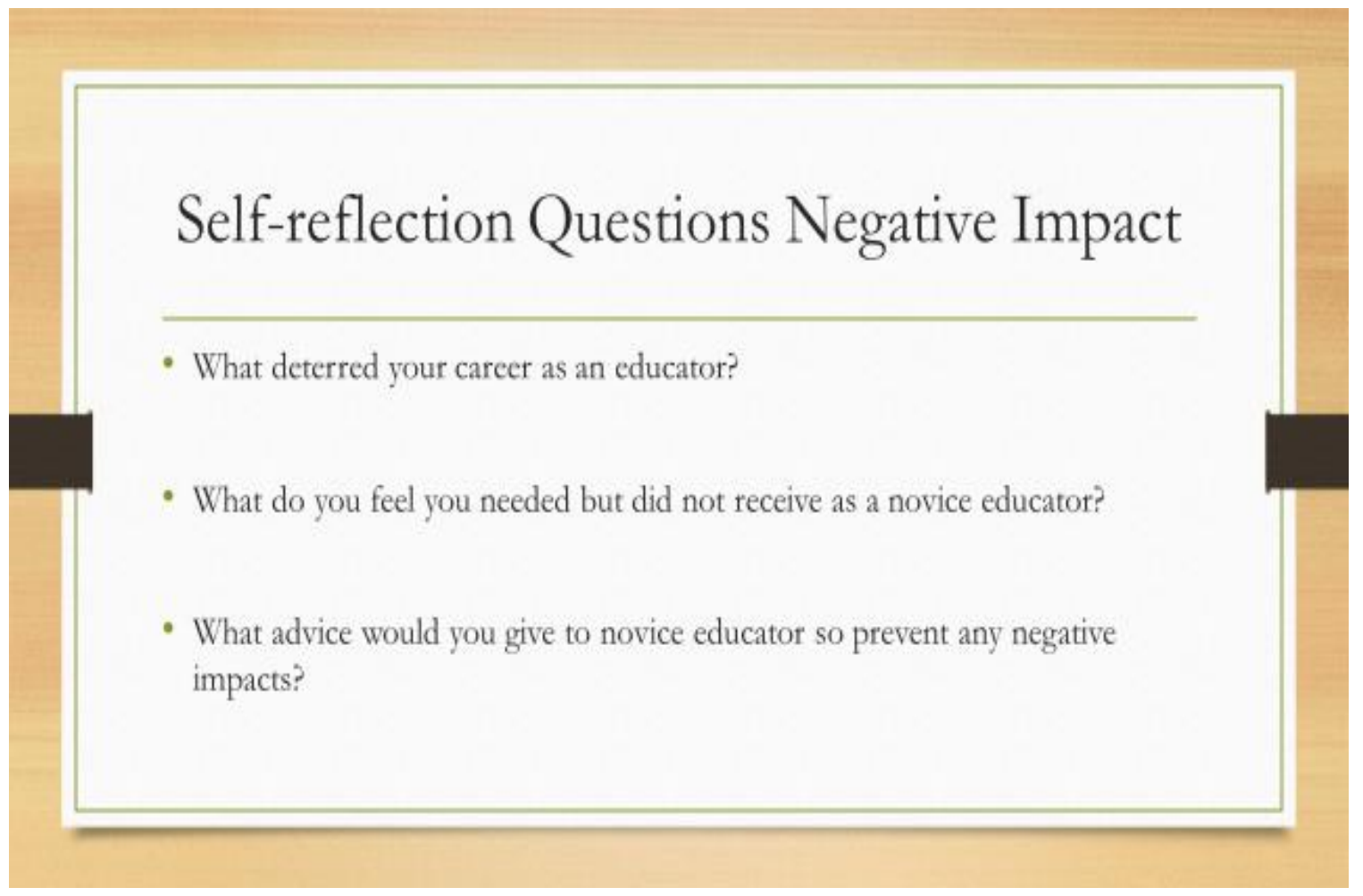




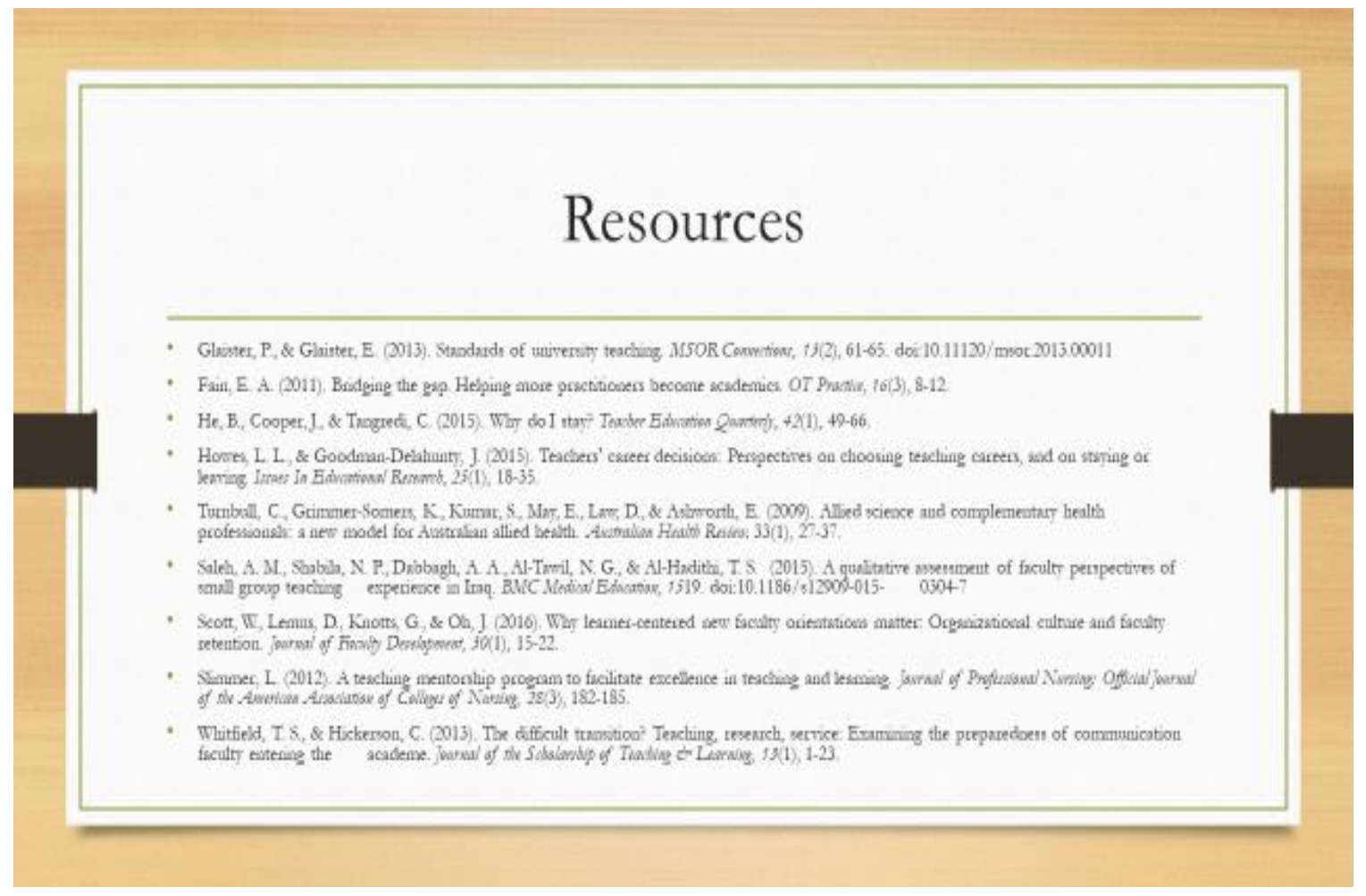


Evaluation Form - The Importance of a Support System for New Faculty Members

Day 1

Any Suggestions for Improvement to this Presentation?

What suggestions do you have for future development?

What ideas will you incorporate for your Program?

Any additional information you would like to add to this presentation? 


\section{$\underline{\text { Session Day } 2}$}

Topic: Examples of Orientation, Mentorship and Professional Development

Time: 2 - 3 hr Morning Session and 2 - 3 hr Afternoon Session

Discussion: What types of examples of orientation, mentorship and professional development systems have been identified in current literature and recent research.

\begin{tabular}{|c|c|c|c|c|}
\hline Topic & Materials & Activities & $\begin{array}{c}\text { Time } \\
\text { Allotment }\end{array}$ & Goals \\
\hline $\begin{array}{l}\text { Orientation to the } \\
\text { Institution }\end{array}$ & Induction Package & $\begin{array}{l}\text { Interactive review } \\
\text { of orientation to } \\
\text { the institution }\end{array}$ & 1 hour & $\begin{array}{c}\text { Gain familiarity of } \\
\text { orientation } \\
\text { examples }\end{array}$ \\
\hline $\begin{array}{l}\text { Orientation to the } \\
\text { Department }\end{array}$ & Induction Package & $\begin{array}{l}\text { Interactive review } \\
\text { of orientation to } \\
\text { the program }\end{array}$ & 30 minutes & $\begin{array}{c}\text { Gain familiarity of } \\
\text { orientation } \\
\text { examples }\end{array}$ \\
\hline Break & & & 10 minutes & \\
\hline $\begin{array}{c}\text { Mentor } \\
\text { Assignment }\end{array}$ & Induction Package & $\begin{array}{c}\text { Interactive review } \\
\text { of the significance } \\
\text { of mentor } \\
\text { assignment } \\
\end{array}$ & 1 hour & $\begin{array}{c}\text { Gain familiarity of } \\
\text { mentor } \\
\text { assignment } \\
\text { examples } \\
\end{array}$ \\
\hline Lunch & & & 1 hour & \\
\hline $\begin{array}{c}\text { Discussion about } \\
\text { the importance of } \\
\text { positive Mentor } \\
\text { relationships }\end{array}$ & Induction Package & & 30 minutes & $\begin{array}{l}\text { Understand ways } \\
\text { to provide positive } \\
\text { mentorship. Take } \\
\text { learned materials } \\
\text { and activities back } \\
\text { to new faculty } \\
\text { members }\end{array}$ \\
\hline $\begin{array}{l}\text { Professional } \\
\text { Development } \\
\text { Opportunities }\end{array}$ & $\begin{array}{l}\text { Induction } \\
\text { Package }\end{array}$ & & 1 hour & $\begin{array}{l}\text { Understand ways } \\
\text { to provide } \\
\text { professional } \\
\text { development. } \\
\text { Take learned } \\
\text { materials and } \\
\text { activities back to } \\
\text { new faculty } \\
\text { members }\end{array}$ \\
\hline $\begin{array}{l}\text { Example follow- } \\
\text { up Meeting }\end{array}$ & Induction Package & & 30 minutes & $\begin{array}{l}\text { Understand } \\
\text { examples of how } \\
\text { to provide support } \\
\text { through follow-up } \\
\text { meetings. Take } \\
\text { learned materials } \\
\text { and activities back }\end{array}$ \\
\hline
\end{tabular}




\begin{tabular}{|c|c|l|l|c|}
\hline & & & & $\begin{array}{c}\text { to new faculty } \\
\text { members }\end{array}$ \\
\hline $\begin{array}{c}\text { Wrap up and } \\
\text { Evaluation }\end{array}$ & Daily Evaluation & & 30 minutes & \\
\hline
\end{tabular}




\section{Orientation to the University}

Example: A new faculty member's introduction to the institution is critical. Whether the university provides orientation or a department administrator or designate, a new faculty member must be given some sort of expectation on their first day. The following is a checklist of recommended items that should be covered on Day 2:

\begin{tabular}{|l|l|l|}
\hline \multicolumn{1}{|c|}{ Topic } & Completed \\
\hline Welcome and Overview of & & \\
the University & & \\
\hline Navigating the University & & \\
\hline Creating Safe and Respectful & & \\
Academic Cultures & & \\
\hline Introduction to Learning & & \\
Management Software & & \\
\hline Introduction to the Office of & & \\
Teaching and Learning & & \\
& & \\
\hline
\end{tabular}




\begin{tabular}{|l|l|l|}
\hline Introduction to the & & \\
University Library and & & \\
Resources & & \\
\hline Overview of the & & \\
\hline Expectations for Teaching & & \\
\hline Policies that Apply to your & & \\
Program & & \\
\hline Handout of the University's & & \\
Heirarchy, possible & & \\
Introductions & & \\
\hline Handout of Important & & \\
University Phone Numbers & & \\
\hline
\end{tabular}




\section{Orientation to the Department}

Example: A new faculty member's introduction should include introduction and acclimation of their department. Whether the department chair, Dean or designate administrator, a new faculty member must be given some sort of expectations about their role on their second day. The following is a checklist of recommended items that should be covered on Day 2:

\begin{tabular}{|l|l|l|}
\hline \multicolumn{1}{|c|}{ Topic } & Discussion Points & Completed \\
\hline Welcome and Overview of the & & \\
Introduction to Faculty & & \\
\hline Reading Department Policies & & \\
\hline Teaching & & \\
\hline Discussion about Expectation for & & \\
\hline Service & & \\
\hline Discussion about Expectation for & & \\
\hline Discussion about Expectation for & & \\
& & \\
\hline
\end{tabular}




\begin{tabular}{|l|l|l|}
\hline & & \\
\hline $\begin{array}{l}\text { Discussion about their experience } \\
\text { with } \\
\text { classroom Teaching and Need for } \\
\text { further support }\end{array}$ & & \\
\hline $\begin{array}{l}\text { Discussion about their experience } \\
\text { with Instructional Methodology } \\
\text { and Need for further support }\end{array}$ & & \\
\hline $\begin{array}{l}\text { Discussion about their experience } \\
\text { with Educational Technology and } \\
\text { Need for further support }\end{array}$ & & \\
\hline piscussion about the desire to & & \\
pursue a Mentor Relationship & & \\
\hline Phone Numbers & & \\
\hline Clarification or Expansion & & \\
Discussion from University & & \\
Orientation & & \\
\hline Handout of Important Department & & \\
\hline
\end{tabular}




\section{Mentor Assignment}

Example: A new faculty member's introduction should include the need to pursue a mentor relationship. The needs of the new faculty member must be sought in order to for the mentor/ mentee relationship to be positive. Whether the department chair, Dean or designate administrator, a new faculty member's needs about an assigned mentor, terms of the relationship, and frequency of meetings should be discussed on their third day. The following is a checklist of recommended items that should be covered on Day 2:

\begin{tabular}{|c|c|c|}
\hline Needs of Mentee & Discussion Points & Completed \\
\hline $\begin{array}{l}\text { What are the research goals } \\
\text { of mentee? }\end{array}$ & & \\
\hline $\begin{array}{l}\text { What are the teaching } \\
\text { philosophies of the mentee? }\end{array}$ & & \\
\hline $\begin{array}{l}\text { What are the service goals } \\
\text { of the mentee? }\end{array}$ & & \\
\hline $\begin{array}{l}\text { Do they prefer a mentor } \\
\text { within the program or } \\
\text { outside? }\end{array}$ & & \\
\hline $\begin{array}{l}\text { What areas does the mentee } \\
\text { feel least prepared? }\end{array}$ & & \\
\hline $\begin{array}{l}\text { What does the mentee } \\
\text { require from a mentor } \\
\text { relationship? }\end{array}$ & & \\
\hline $\begin{array}{l}\text { How frequently would the } \\
\text { mentee like to meet? }\end{array}$ & & \\
\hline
\end{tabular}




\section{Positive Assignments of Mentor/ Mentee Relationship}

\begin{tabular}{|c|c|c|}
\hline Requirements of a Mentor & Discussion Points & Completed \\
\hline $\begin{array}{l}\text { Is the desired mentor willing } \\
\text { to be a model for the new } \\
\text { faculty member? }\end{array}$ & & \\
\hline $\begin{array}{l}\text { Is this mentor eager to share } \\
\text { information and ideas with } \\
\text { colleagues? }\end{array}$ & & \\
\hline $\begin{array}{l}\text { Does this mentor exhibit a } \\
\text { commitment to lifelong } \\
\text { learning? }\end{array}$ & & \\
\hline $\begin{array}{l}\text { Does this mentor have } \\
\text { excellent knowledge of } \\
\text { pedagogy and subject matter } \\
\text { relevant to the mentee? }\end{array}$ & & \\
\hline $\begin{array}{l}\text { Does this mentor feel } \\
\text { comfortable being observed } \\
\text { by others? }\end{array}$ & & \\
\hline
\end{tabular}




\begin{tabular}{|l|l|l|}
\hline Does this mentor articulate & & \\
effective instructional & & \\
strategies? & & \\
Is this mentor able to & & \\
professional relationship? & & \\
\hline Is this mentor easily & & \\
approachable? & & \\
\hline Does this mentor share the & & \\
same teaching philosophies & & \\
as the mentee? & & \\
\hline
\end{tabular}




\section{Professional Development Opportunities}

Example: A new faculty member's professional development opportunities are important for their success. Whether the university, department administrator or designate provides information about professional development networks, a new faculty member must have some discussion about this topic on their fourth day. The following is a checklist of recommended items that should be covered on Day 2:

\begin{tabular}{|l|l|l|}
\hline \multicolumn{1}{|c|}{ Topic } & Completed \\
\hline request development in & & \\
teaching practice? & & \\
\hline Does the faculty member & & \\
request development in & & \\
instructional methodology? & & \\
\hline $\begin{array}{l}\text { Does the faculty member } \\
\text { request development in }\end{array}$ & & \\
educational technology? & & \\
\hline Does the faculty member & & \\
request development in & & \\
research? & & \\
\hline
\end{tabular}




\begin{tabular}{|l|l|l|}
\hline Does the faculty member & & \\
request development in & & \\
colleague networking? & & \\
\hline Does the faculty member & & \\
request development in an & & \\
area of clinical expertise? & & \\
\hline Are there any areas of interest & & \\
that were not mentioned & & \\
above? & & \\
\hline
\end{tabular}




\section{Follow-Up Meeting Administration}

Example: An administrative follow-up meeting should conclude the induction package. A department administrator or designate should follow-up with the new faculty member at the end of their first week to ensure all their needs were met and ensure they have a successful plan and path toward the academic career. The following is a checklist of recommended items that should be covered on Day 2:

\begin{tabular}{|l|l|l|}
\hline \multicolumn{1}{|c|}{ Topic } & \multicolumn{1}{|c|}{ Discussion Points } & Completed \\
\hline Are there any questions or & & \\
concerns about the University? & & \\
concerns about Navigating the & & \\
University? & & \\
\hline Are there any questions or & & \\
concerns about Learning & & \\
Management Software? & & \\
\hline Are there any questions or & & \\
concerns about the Office of & & \\
Teaching and Learning? & & \\
\hline
\end{tabular}




\begin{tabular}{|l|l|l|}
\hline Are there any questions or & & \\
concerns about the University & & \\
Library and Resources? & & \\
concerns about the expectations & & \\
for teaching? & & \\
\hline Are there any questions or & & \\
concerns about the expectations & & \\
for service? & & \\
\hline Are there any questions or & & \\
concerns about the expectations & & \\
for scholarship? & & \\
\hline Are there any questions or & & \\
concerns about the Policies that & & \\
Apply to your Program? & & \\
\hline Are there any questions or & & \\
\hline Is there a mentor assigned? & & \\
\hline
\end{tabular}




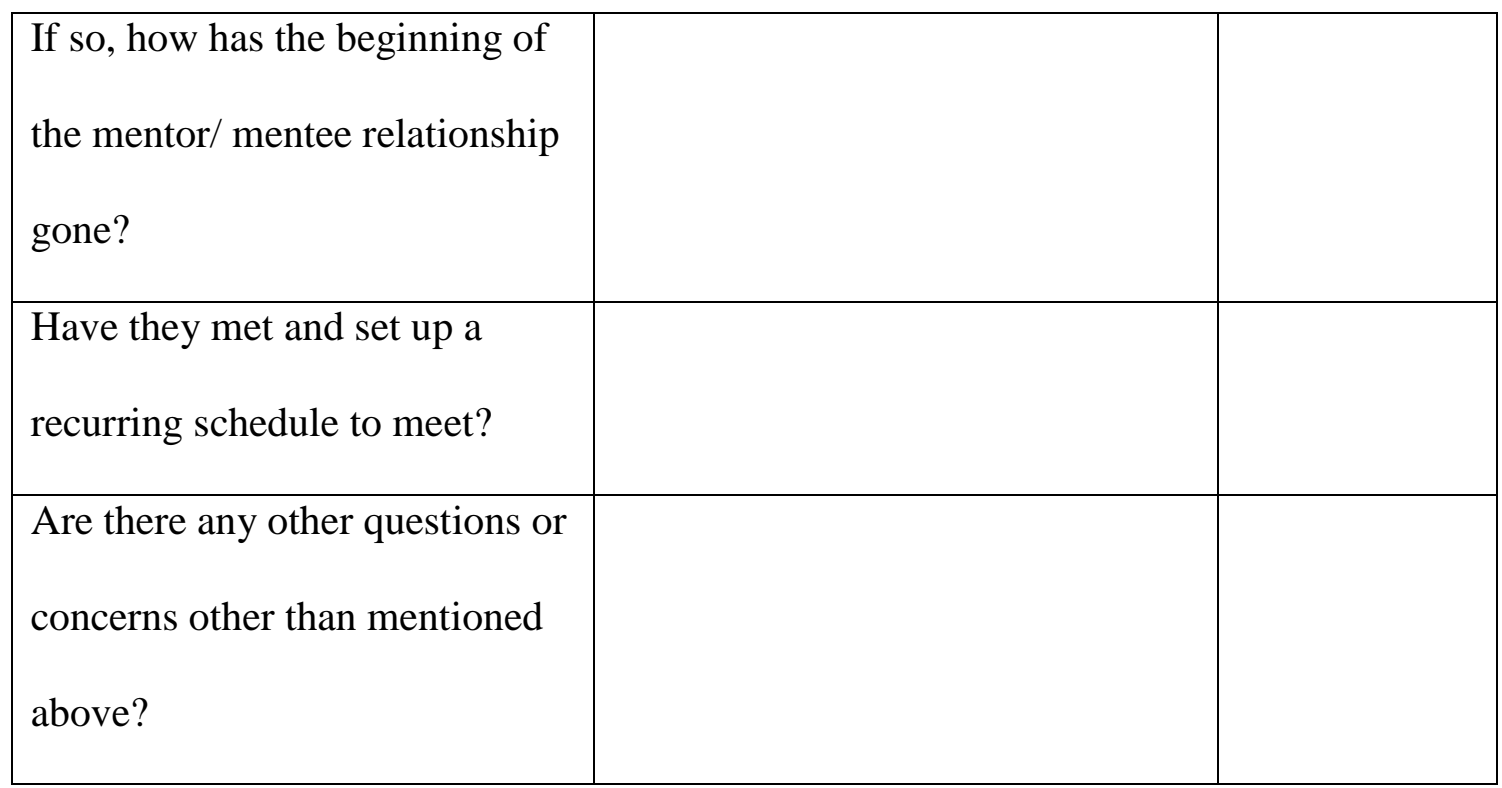


Evaluation Form - Examples of Orientation, Mentorship and Professional Development

Day 2

Any Suggestions for Improvement to this Induction package?

What suggestions do you have for future development?

What ideas will you incorporate for your Program?

Any additional information you would like to add to this induction package? 